\title{
Decision and Coordination of Low-Carbon E-Commerce Supply Chain with Government Carbon Subsidies and Fairness Concerns
}

\author{
Qiang Han $\mathbb{D}^{1},{ }^{1}$ Yuyan Wang $\mathbb{D},{ }^{1}$ Liang Shen, ${ }^{2}$ and Wenquan Dong $\mathbb{D}^{3,4}$ \\ ${ }^{1}$ School of Management Science and Engineering, Shandong University of Finance and Economics, Jinan, \\ Shandong 250014, China \\ ${ }^{2}$ School of Public Finance and Taxation, Shandong University of Finance and Economics, Jinan, Shandong 250014, China \\ ${ }^{3}$ Institute for a Secure and Sustainable Environment, The University of Tennessee, Knoxville, Tenn 37996, USA \\ ${ }^{4}$ Department of Industrial and Systems Engineering, The University of Tennessee, Knoxville, Tenn 37996, USA
}

Correspondence should be addressed to Yuyan Wang; wangyuyan1224@126.com

Received 31 May 2020; Revised 16 July 2020; Accepted 30 July 2020; Published 24 August 2020

Academic Editor: Juan Carlos Cortés

Copyright (c) 2020 Qiang Han et al. This is an open access article distributed under the Creative Commons Attribution License, which permits unrestricted use, distribution, and reproduction in any medium, provided the original work is properly cited.

\begin{abstract}
More low-carbon products help fight climate change and environmental problems. Governments consider encouraging the manufacturer's initiative of producing low-carbon products by providing subsidies. However, when the manufacturer sells lowcarbon products through the e-commerce platform, fairness concerns arise because of the profit difference. So, this paper builds game models to study decision behavior in the low-carbon e-commerce supply chain when the manufacturer receives government carbon subsidies and has fairness concerns. Our findings show that consumers' preference for low-carbon products will be conducive to the operation of the supply chain. So it is necessary to popularize low-carbon products. The effect of government subsidies on supply chain decisions is different from fairness concerns. Government subsidies are positive factors in the supply chain operation, which can stimulate the manufacturer to make low-carbon products as expected and choose the high quality-high price development mode. This will help improve the profit of enterprises in the supply chain but cannot effectively stimulate the e-commerce platform to increase its service level. By contrast, the manufacturer's fairness concerns are negative factors, which make the manufacturer prefer to adopt a low quality-low price development mode to improve their utility. This offsets the positive effect of government subsidies. It turns out that the profit of both node enterprises and the supply chain system has declined. But, fairness concerns are an important way to express the manufacturer's demand. Finally, the joint allocation contract of cost and profit designed by comprehensively considering the effect of government subsidies and fairness concerns can make the supply chain coordinated. However, even as positive factors, only within a specific range do government subsidies help coordinate the supply chain, but not the more, the better.
\end{abstract}

\section{Introduction}

With the environmental problems being more and more concerned, low-carbon products that can save energy and reduce carbon emission have gradually become consumption trends, for example, energy-saving light, inverter, and air conditioner. But, producing low-carbon products requires an update of the production process and equipment, which leads to an increase in manufacturers' cost. For encouraging manufacturers to produce low-carbon products, the government generally gives them some carbon subsidies, thereby effectively increasing the production of low-carbon products $[1,2]$. In the 2013 home appliance sales of China, energy-saving subsidy policy drove the promotion of more than 32.7 million energy-efficient home appliances, as much as USD 18.9 billion (http://www.chinairn.com/news/ 20130523/100849491.html).

Since the 1990s, the rapid development of the network technology and express delivery industry has attracted more and more consumers to purchase online. A number of e-commerce platforms (abbreviated as platform in the following if no ambiguity) come into being, for instance, Amazon, JD.com, and Tmall. In 2019, online sales of Black Friday reached USD 7.4 billion, up 19.2 percent from 2018 and setting a new 
high (https://www.cnbc.com/2019/11/29/black-friday-onlinesales-up-19percent-by-9-am-thanksgiving-sales-hit-recordonline.html); total sales of Tmall Double 11 Shopping Festival pulled in USD 38.4 billion from 220 countries and regions worldwide, and 299 merchants have total revenues of over USD 14.3 million each (https://alibabagroup.com/en/news/article? news $=\mathrm{p} 191112$ ). More and more manufacturers sell products through e-commerce platforms, and these manufacturers are mainly small and medium sized. For example, in 2017, more than 20,000 Amazon online sellers across the world exceeded USD 1 million in sales (https:/www.marketplacepulse.com/ articles/twenty-thousand-amazon-millionaire-sellers).

The e-commerce platform provides manufacturers with new sale channels to sell low-carbon products. Therefore, the platform and low-carbon product manufacturers form a low-carbon e-commerce supply chain. This cooperation seems to be mutually beneficial. However, there are still some discordant factors in the operation process. The e-commerce supply chain is very different from the traditional one that the platform, because of its vast network traffic, becomes the leader. The platform formulates rules for manufacturers' entry and controls the information flow, goods flow, and capital flow. In contrast, manufacturers not only have to pay a specific fixed fee to the platform for entering it but also share the sales profit as a commission with the platform according to an established proportion. In practice, Tmall, JD.com, and Dangdang.com charge their settled manufactures in this way. Moreover, as a shared medium, the platform usually attracts many manufacturers such that it can achieve substantial profit, so sometimes would ignore the manufacturers' interests by using its dominant position. In particular, small- and medium-sized manufacturers are even more affected. For example, during the 6-18 promotion of 2017, many manufacturers have expressed strong dissatisfaction with Tmall and JD.com because these sellers were forced to participate in large-scale discount activities (https://www.chinainternetwatch.com/ 29999/double-11-2019/). As a result, the decline in status and the gap in profitability in the supply chain has led manufacturers to reexamine their relationship with the platform, which is called fairness concerns. The larger the platform's size, the more significant the income gap, and the stronger the concerns of small- and medium-sized manufacturers in the platform.

This kind of fairness concerns of manufacturers is an instinct response protecting their interests. Then, when they have fairness concerns, how do manufacturers react to the platform, and what impact will they have on the decision of the low-carbon e-commerce supply chain system? When government subsidies and fairness concerns coexist, what will happen to the decision of the supply chain system? When manufacturers have fairness concerns, how could the system coordination be achieved? The current research fruits are still not able to address the above problem well. At present, the research about fairness concern behavior is mainly focused on the traditional offline supply chain [3-5]. Even if the online sale is considered, it is only regarded as one of the distribution channels, which does not reflect the key features of a platform [6-8]. As the leader of a low- carbon e-commerce supply chain, the platform is responsible for providing consumers with logistics, information, and other services besides general services, and consumers demand much more from the platform than from offline sellers. Therefore, the operation of the platform requires costs to maintain, and it is also necessary to take the platform's service cost and service level into account when making decisions. Moreover, manufacturers' carbon subsidies obtained from the government make manufacturers realize the importance of their carbon emission reduction behavior, which will intensify manufacturers' desire for fairness. These are rarely addressed in the existing research.

This paper will study how the low-carbon e-commerce supply chain will make decisions and be coordinated if the manufacturer receives carbon subsidies from the government and has fairness concerns. Our contributions are as follows:

(1) To determine whether the carbon subsidies are effective to promote the low-carbon products by analyzing the effect of the carbon subsidies on the manufacturer's sales price and carbon emission reduction level, the platform's service level, and the profit of the low-carbon e-commerce supply chain.

(2) To explore the transmission mechanisms of the manufacturer's fairness concerns by analyzing the double effects of both carbon subsidies and the manufacturer's fairness concerns on the service level, the sales price, and the profit.

(3) To coordinate the supply chain with government carbon subsidies and fairness concerns by designing the joint allocation contract of cost and profit to eliminate the double marginalization under decentralized decision modes.

The rest of this paper is organized as follows. Literature review is given in Section 2. Some basic work for the models is provided in Section 3. We model four different decision modes in Section 4 and then analyze and compare different decision results in Section 5. In Section 6, the coordination mechanism for the supply chain system is designed. In Section 7, we do the example analysis. In Section 8, we offer concluding comments.

\section{Related Literature}

This paper mainly involves such three streams of literature: incentive mechanism of government carbon subsidies, supply chain fairness concerns, and supply chain coordination.

2.1. Incentive Mechanism of Government Carbon Subsidies. For protecting our environment, researches about closedloop supply chain have been conducted [9-11]. As carbon emission reduction is concerned, manufacturers have a direct relation to assume this responsibility and also manage to invest in this area [12]. In fact, economic and environmental benefits can be achieved simultaneously [13], and external factors could do something to guide the 
manufactures and the supply chain $[14,15]$. Recently, for promoting the production and consumption of low-carbon products, governments of the world are concerned about how the supply chain decision-making will be influenced by different carbon emission reduction measures [16]. Carbon subsidies, often adopted by governments to promote product development, can boost profit growth, increase market demand, and improve the benefits of supply chain members [17]. Currently, carbon subsidies are mainly used in the field of recycling or remanufacturing of electronic products [18]. Li et al. [19] considered the application of carbon subsidy policies in the remanufacturing supply chain and analyzed when and how the government should use carbon subsidies to stimulate enterprises' initiative to reduce carbon emissions. In practice, there are two departments: formal and informal sections, which can recycle electronic products. In order to accelerate the development of the recycling industry, subsidies should be regulated by the government to limit the waste quality to a higher level. If the government subsidies are not sufficient and the waste quality is high, then the informal production sector has a greater competitive advantage [20]. As the subsidy recipient is concerned, the government could subsidize the recycler or remanufacturer and provide subsidies according to the remanufacturers' different service levels, which is helpful to expand the market scale and remanufacturing service level [21].

The carbon subsidy strategy studied in the existing literature is a passive way mainly aiming at the remanufacturing and waste recycling in the traditional supply chain background. However, under the e-commerce environment, the transmission mechanism of government carbon subsidies in the supply chain will be quite different, where the manufacturer directly sells products to consumers on the platform and the low-carbon product manufacturer, as the main contributor to manufacturing low-carbon products can set the product price. Therefore, the government gives carbon subsidies to the low-carbon product manufacturer. After obtaining carbon subsidies, the manufacturer's profit will be raised, and then, this influence will be passed on through the supply chain, which will further affect some decisions of the platform. This means that the existing methodology is no longer applicable. So, from the perspective that the government actively encourages the manufacturer to produce low-carbon products by providing carbon subsidies, this paper introduces carbon emission reduction costs and carbon subsidies into the manufacturer's profit function. Carbon subsidies will be given proportional to the carbon emission level. We aim to drive the production of low-carbon products from the source.

2.2. Supply Chain Fairness Concerns. Besides how much profit they earn, companies or individuals in economic activities will also pay close attention to the profit gap between the trade parties, that is, the fairness of profit allocation [22-24]. At present, the concerns about fairness are particularly reflected in the offline supply chain that maintains long-term partnerships [25-27]. Cui et al. [28] used fairness concerns to express dissatisfaction with the status in the supply chain and explore how the transactions between retailers and manufacturers would be affected, especially by quantity discounts and two-part tariffs. Zhao et al. [29] studied a product and service supply chain and compared its optimal pricing strategy in two cases based on whether fairness concerns of the retailer are considered, finding that if the retailer in the supply chain has fairness concerns, all the enterprises could adopt differentiated service pricing strategies, but the retailer's fairness concerns would do harm to the manufacturer's profit. If both manufacturers and retailers in the supply chain have fairness concerns, retailers' fairness concerns are more likely to result in a narrower supply chain stable area than manufacturers, while manufacturers' fairness concerns can expand the system's stable area $[30,31]$.

The existing research fruits mainly study the fairness concerns of retailers and manufacturers in the supply chain of ordinary products. The research subject of this paper is the fuse of the e-commerce supply chain and low-carbon supply chain. Manufacturers produce low-carbon products and need to invest in additional R\&D costs. The e-commerce platform in the supply chain is the dominant and core enterprise, which puts manufacturers at a disadvantage status in the profit allocation, thereby making manufacturers have fairness concerns. Moreover, fair concerns in this situation have their particularity. On the one hand, the platform could get commissions from numerous small- and medium-sized manufacturers that have settled in it; and on the other hand, manufacturers think that they should get more benefits because of paying for low-carbon production costs and receiving government subsidies. So, even though the manufacturer's profit is no less than what the e-commerce platform can get from this manufacturer, the manufacturer will still have fairness concerns. Thus, the mechanism of how fairness concerns come into being in this paper is different from the existing research fruits.

\subsection{Supply Chain Coordination. Classic coordination con-} tracts include sharing revenue contract, buy-back contract, quantity-flexibility contract, wholesale pricing contract, and quantity discount contract [32]. Now, researchers have to add some other factors into the coordination contract, such as environmental, economic, and social dimensions [33-40]. For the two-tier reverse supply chain, Heydari et al. [41] proposed a coordination mechanism combining quantity discounts with increasing fee, adding government subsidies into the contract as incentives so that each member has enough initiative to participate in the coordination process, which favors retailers much more. For a low-carbon supply chain with carbon emission cap-and-trade, Peng et al. [42] combined subsidy on emission reduction with the revenuesharing contract and then perfectly achieved both the supply chain coordination and the carbon emission reduction.

For the supply chain coordination problems with fairness concerns, many scholars have also designed effective coordination contracts according to practical problems [43-45]. Cui et al. [28] designed the whole price contract and 
used this contract to coordinate fairness concerns from retailers only or from both retailers and manufacturers in the supply chain with linear demand. Then, Caliskan-Demiraga et al. [46] extended the linear demand function to the exponential one and found that when retailers have fairness concerns, more relaxed conditions are needed to achieve coordination. Zheng et al. [47] coordinated a closed-loop supply chain by variable-weighted Shapley values, which is better than the traditional Shapley value coordination method when remanufactured goods are accepted by customers at a lower rate.

One supply chain contract cannot apply to all coordination problems, and we need to design them according to the actual ones. The existing literature about supply chain coordination has not considered the existence of both fairness concerns and carbon subsidies. In addition, the difference in the problem addressed here from the existing literature lies in that it is necessary to take four factors into account, that is, the manufacturer's lowcarbon cost, the platform's service cost, the commission charged by the platform, and government carbon subsidies, which are critical for achieving coordination. We have to balance the four factors and explore how the coordination condition is influenced by manufacturers' fairness concerns.

Based on the above literature review, the existing research has built a solid base for the related fields; however, there are still research gaps to fill. First, most works studied carbon subsidy strategy for recycling or remanufacturing of electronic products [18-21]; although several studies have investigated supply chains under the governments' carbon subsidy $[12,14$, 15], they are not applied to the e-commerce supply chain. Second, fair concerns exist in different backgrounds, but most of them studied that between the retailers and manufacturers in the supply chain of ordinary products $[24,27,29,31]$; even though there are researches related to online or low-carbon background, they do not consider them together [23,30]. Third, various coordination contracts have been designed aiming to reduce the carbon emission or protect the environment $[32,36]$, and some of them have taken government role [41], low-carbon preference [42], or fairness concern [44] into account, but no works addressed the problem with all of them; under the e-commerce background, Wang et al. [48] coordinated the supply chain when the manufacturer has fairness concerns, but no carbon subsidy is considered. So, in this paper, our contributions are to formulate the game model for low-carbon e-commerce supply chain with government carbon subsidies and fairness concerns, exploring the effect of government carbon subsidies and fairness concerns on the supply chain, determining what the manufacturer and the platform will react, achieving the coordination of the supply chain by allocating the carbon subsidies, commission, and the cost as a whole.

\section{Preliminaries of Models}

We consider a supply chain composed of one e-commerce platform and one small- and medium-sized manufacturer. In this supply chain, the manufacturer is responsible for producing only one low-carbon product, while the platform offers a direct online shop to the manufacturer. Because the fixed fee pays only once when the manufacturer enters the platform, we do not take it into account in the following models.

The platform and the manufacturer are independent, making decisions for maximizing their profit, respectively. They form Stackelberg games. As stated in Section 1, this paper assumes that the platform is the leader with the priority to make decisions, while the manufacturer is the follower. The platform first determines its service level. On obtaining the platform's decision, the manufacturer then determines sales price of the low-carbon product and its carbon emission reduction level.

Some notations are listed in Table 1, which will be used frequently in this paper.

Generally, carbon emission reduction involves more advanced technology and management, so the manufacturer has to spend more extra cost for producing the low-carbon product than general ones. The higher the carbon emission reduction level, the higher the cost. Based on the relation put forward by Nair and Narasimhan [49], the manufacturer's carbon emission reduction cost is as follows:

$$
C_{m}(h)=\frac{t h^{2}}{2} .
$$

Because carbon emission reduction is conducive to energy conservation and environmental protection, the government will provide the manufacturer with subsidies to encourage its positive behavior. Suppose the unit emission reduction subsidy received by the manufacturer is $T(T>0)$.

According to Yao and Liu [50], the demanded quantity of low-carbon product depends on its sales price, the manufacturer's carbon emission reduction level, and the platform's service level, which can be formulated as

$$
q=D-d_{1} p+d_{2} s+d_{3} h
$$

Suppose $D$ is a large enough constant number. Suppose $d_{1}>d_{3}$, suggesting that the product's price influences consumers much more than its low-carbon level.

Generally, the higher the platform's service level, the more the cost. Based on Shen's research [51], the platform's service cost is functioned as

$$
C_{e}(s)=\frac{k s^{2}}{2} .
$$

Suppose $\rho<p-c$, representing that the commission should be less than the net profit of the product sales.

To make the following analysis hold, we further assume $t d_{1}<d_{3}^{2}<2 t d_{1}$ and $t d_{2}^{2}+k d_{3}^{2}<2 k t d_{1}$. The former, equivalent to $2 d_{1} C_{m}(h)<\left(d_{3} h\right)^{2}<4 d_{1} C_{m}(h)$, means that the influence of the manufacturer's carbon emission reduction level on the demanded quantity of the low-carbon product depends on the carbon emission reduction cost, and the influence is limited, neither too large nor too little, while the latter represents that the sales price has greater influence on the demanded quantity than the combined effect of the manufacturer's carbon emission reduction level and the platform's service level. 
TABLE 1: Mathematical notations.

\begin{tabular}{lc}
\hline Notations & Meaning \\
\hline$c$ & Unit cost for producing the low-carbon product (in dollars) \\
$h$ & Carbon emission reduction level of the manufacture \\
$p$ & Sales price of the low-carbon product (in dollars) \\
$q$ & Market demand for the low-carbon product \\
$s$ & Service level of the platform \\
$T$ & Unit government subsidy for the manufacture (in dollars) \\
$\rho$ & Commission charged by the platform for unit sales of products (in dollars) \\
$t$ & Carbon emission reduction cost coefficient \\
$D$ & Maximum quantity demanded of the low-carbon product \\
$d_{1}$ & Influence coefficient of the low-carbon product sales price on demand \\
$d_{2}$ & Influence coefficient of the platform's service level on demand \\
$d_{3}$ & Influence coefficient of the manufacturer's carbon emission reduction level on demand \\
$k$ & Service cost coefficient \\
\hline
\end{tabular}

\section{Modeling Framework}

In this section, we model different decision modes of the e-commerce supply chain according to whether there are government carbon subsidies and manufacturer's fairness concerns or not.

4.1. Model I: Benchmark Model. Starting from the most fundamental case, we build the benchmark model in which the government does not provide any carbon subsidies and the manufacturer does not have fairness concerns. We can also call it the decentralized decision model without government carbon subsidies and manufacturer's fairness concerns. Then, the manufacturer's profit is

$$
\pi_{m}=p q-\rho q-c q-\frac{t h^{2}}{2} .
$$

The platform's profit is

$$
\pi_{e}=\rho q-\frac{k s^{2}}{2} .
$$

The supply chain's profit is

$$
\pi=p q-c q-\frac{t h^{2}}{2}-\frac{k s^{2}}{2} .
$$

By backward induction, the optimal solution of this model could be achieved as follows.

Theorem 1. In the benchmark model, the optimal sales price is

$p^{b *}=(c+\rho)+d_{1} \cdot\left(\frac{t d_{2}}{2 t d_{1}-d_{3}^{2}}\right)^{2} \cdot \frac{\rho}{k}+\frac{k\left[D-d_{1}(c+\rho)\right]-\rho d_{2}^{2}}{k\left(2 t d_{1}-d_{3}^{2}\right)} \cdot t$.

The optimal carbon emission reduction level is

$$
h^{b *}=t \cdot d_{1} \cdot d_{3} \cdot \frac{\rho}{k} \cdot\left(\frac{d_{2}}{2 t d_{1}-d_{3}^{2}}\right)^{2}+d_{3} \cdot \frac{k\left[D-d_{1}(c+\rho)\right]-d_{2}^{2} \rho}{k\left(2 t d_{1}-d_{3}^{2}\right)} .
$$

$$
s^{b *}=d_{2} \cdot \frac{\rho}{k} \cdot \frac{d_{3}^{2}-t d_{1}}{2 t d_{1}-d_{3}^{2}} .
$$

The manufacturer's optimal profit is

$\pi_{m}^{b *}=\frac{t}{2} \cdot \frac{\left[D-d_{1}(c+\rho)\right]^{2}}{2 t d_{1}-d_{3}^{2}}-\frac{t}{2} \cdot \frac{d_{2}^{4}}{2 t d_{1}-d_{3}^{2}} \cdot\left(\frac{\rho}{k} \cdot \frac{d_{3}^{2}-t d_{1}}{2 t d_{1}-d_{3}^{2}}\right)^{2}$.

The platform's optimal profit is

$$
\pi_{e}^{b *}=t \rho d_{1} \cdot \frac{D-d_{1}(c+\rho)}{2 t d_{1}-d_{3}^{2}}+\frac{\left(\rho d_{2}\right)^{2}}{2 k} \cdot\left(\frac{d_{3}^{2}-t d_{1}}{2 t d_{1}-d_{3}^{2}}\right)^{2} .
$$

The supply chain's optimal profit is

$$
\begin{aligned}
\pi^{b *}= & t \cdot \frac{\left[D-d_{1}(c-\rho)\right] \cdot\left[D-d_{1}(c+\rho)\right]}{2\left(2 t d_{1}-d_{3}^{2}\right)}+\frac{\left(\rho d_{2}\right)^{2}}{2 k} \\
& \cdot\left(\frac{d_{3}^{2}-t d_{1}}{2 t d_{1}-d_{3}^{2}}\right)^{2}-\frac{t d_{2}^{4}}{2} \cdot\left(\frac{\rho}{k}\right)^{2} \cdot \frac{1}{2 t d_{1}-d_{3}^{2}} \cdot\left(\frac{d_{3}^{2}-t d_{1}}{2 t d_{1}-d_{3}^{2}}\right)^{2} .
\end{aligned}
$$

Proof. See Appendix A.

4.2. Model II: Decentralized Decision Model with Government Carbon Subsidies and without Manufacturer's Fairness Concerns. Based on the benchmark model, we turn to the case that the government subsidies the manufacturer for its carbon emission reduction behavior and the manufacturer does not have fairness concerns. Then, the manufacturer's profit is

$$
\pi_{m}=p q+T h-\rho q-c q-\frac{t h^{2}}{2} .
$$

The platform's profit is

$$
\pi_{e}=\rho q-\frac{k s^{2}}{2} .
$$

The optimal service level is 
The supply chain's profit is

$$
\pi=p q+T h-c q-\frac{t h^{2}}{2}-\frac{k s^{2}}{2} .
$$

Similar to the solution process of Theorem 1, we reach the following theorem.

Theorem 2. In the decentralized decision model with government carbon subsidies, the optimal product sales price is

$$
\begin{aligned}
p^{s *}= & (c+\rho)+\frac{\rho d_{1}}{k} \cdot\left(\frac{t d_{2}}{2 t d_{1}-d_{3}^{2}}\right)^{2} \\
& +\frac{k\left[D t+d_{3} T-t d_{1}(c+\rho)\right]-\rho t d_{2}^{2}}{k\left(2 t d_{1}-d_{3}^{2}\right)} .
\end{aligned}
$$

The optimal carbon emission reduction level is

$$
\begin{aligned}
h^{s *}= & \frac{\rho}{k} \cdot \frac{d_{1} d_{3}}{t} \cdot\left(\frac{t d_{2}}{2 t d_{1}-d_{3}^{2}}\right)^{2}+\frac{d_{3}}{k} \\
& \cdot \frac{k\left[\left(D+2 T d_{1}\right) /\left(d_{3}-d_{1}(c+\rho)\right)\right]-\rho d_{2}^{2}}{2 t d_{1}-d_{3}^{2}} .
\end{aligned}
$$

The optimal service level is

$$
s^{s *}=d_{2} \cdot \frac{\rho}{k} \cdot \frac{d_{3}^{2}-t d_{1}}{2 t d_{1}-d_{3}^{2}}
$$

The manufacturer's optimal profit is

$$
\begin{aligned}
\pi_{m}^{s *}= & \frac{t \cdot\left[D-d_{1}(c+\rho)\right]^{2}+2 d_{3} T\left[D-d_{1}(c+\rho)\right]+2 d_{1} T^{2}}{2\left(2 t d_{1}-d_{3}^{2}\right)} \\
& -\frac{t}{2} \cdot \frac{d_{2}^{4}}{2 t d_{1}-d_{3}^{2}} \cdot\left(\frac{\rho}{k} \cdot \frac{d_{3}^{2}-t d_{1}}{2 t d_{1}-d_{3}^{2}}\right)^{2} .
\end{aligned}
$$

The platform's optimal profit is

$$
\pi_{e}^{s *}=d_{1} \cdot \frac{t \rho\left[D-d_{1}(c+\rho)\right]+T d_{3}}{2 t d_{1}-d_{3}^{2}}+\frac{\left(\rho d_{2}\right)^{2}}{2 k} \cdot\left(\frac{d_{3}^{2}-t d_{1}}{2 t d_{1}-d_{3}^{2}}\right)^{2}
$$

The supply chain's optimal profit is

$$
\pi^{s *}=\frac{t \cdot\left[D-d_{1}(c+\rho)\right]\left[D-d_{1} c-\rho\right]+2 T\left[T d_{1}+\left(D-c d_{1}\right) d_{3}\right]}{2\left(2 t d_{1}-d_{3}^{2}\right)}+\frac{\left(\rho d_{2}\right)^{2}}{2 k} \cdot\left(\frac{d_{3}^{2}-t d_{1}}{2 t d_{1}-d_{3}^{2}}\right)^{2}-\frac{t}{2} \cdot \frac{d_{2}^{4}}{2 t d_{1}-d_{3}^{2}} \cdot\left(\frac{\rho}{k} \cdot \frac{d_{3}^{2}-t d_{1}}{2 t d_{1}-d_{3}^{2}}\right)^{2} .
$$

By comparing the decision results of model II with model I, we can find the effect of government carbon subsidies on the supply chain decision.

Proposition 1. $p^{b *}<p^{s *}, \quad h^{b *}<h^{s *}, \quad s^{b *}=s^{s *}, \pi_{m}^{b *}<\pi_{m}^{s *}$, $\pi_{e}^{b *}<\pi_{e}^{s *}$, and $\pi^{b *}<\pi^{s *}$.

Proof. See Appendix B.

Proposition 1 shows that, after the government provides subsidies, product sales price, carbon emission reduction level, the manufacturer's profit, and the platform's profit have all increased. The proof process in Appendix B also suggests that these changes are related to subsidies, which reflects the effectiveness of government subsidies. However, the platform's service level stays the same. On the one hand, since subsidies are directly given to the manufacturer, they have no impact on the platform's service level. On the other hand, if the platform can have its profit increased even without the necessity to improve its service level, it does not have any initiative to make efforts at all. This reflects the shortcoming of government subsidies since they cannot stimulate the platform to improve its sales service.

Government subsidies express their emphasis and recognition on the manufacturer's production of low-carbon products, which can become a guide to social consumption habits. From the consumers' perspective, their low-carbon awareness will also increase, and they will pay much more attention to the low-carbon level of products when making a purchase. Even if the price is higher than nonlow-carbon products, consumers will be more willing to buy. From the perspective of the manufacturer, government subsidies have given it the motivation and responsibility to continue developing low-carbon products, and its low-carbon level has been constantly improved. The modest increase in the price of the product by the manufacturer mainly reflects a differentiating strategy, which is different from previous products and will eventually make itself more profitable.

On January 16, 2017, JD.com and Midea Group signed a USD 2.9 billion comprehensive strategic cooperation agreement (http://news.163.com/17/0117/10/CAVN0MMQ00018AOQ. html). JD.com has witnessed that prices of low-carbon energy-saving products have generally increased by about USD 87.1. Midea Group received government subsidies of USD 0.2 billion in 2017 (http://money.finance.sina.com.cn/corp/view/ vCB_AllBulletinDetail.php?stockid=000333\&id=4185007) and achieved a year-on-year net profit increase of $17.33 \%$ (http://baijiahao.baidu.com/s? id=1596592651173428121\& wfr=spider\&for=pc). JD.com's full-year net profit in 2017 was USD 0.73 billion, a substantial increase of $140 \%$ year-on-year (http://tech.qq.com/a/20180302/030924. html). 
4.3. Model III: Decentralized Decision Model with Government Carbon Subsidies and Manufacturer's Fairness Concerns. As mentioned in Introduction, the capital input of carbon emission reduction, the dissatisfaction caused by the platform neglecting its interests, and the support of government's carbon subsidies and other factors will cause the manufacturer's concern over the profit gap between it and the platform, thus creating fairness concerns. Therefore, we bring the manufacturer's fairness concern behavior into our model.

According to Fehr and Schmidt [52] and Katok et al. [53], when having fairness concerns, the manufacturer will take $\delta$ times the platform's profit as the reference point. So, we write the manufacturer's utility function as

$$
U_{m}=\pi_{m}-\theta\left(\delta \pi_{e}-\pi_{m}\right),
$$

where $0 \leq \theta \leq 1$ denotes the manufacturer's fairness concern coefficient. When $\theta$ is closer to 0 , it means the manufacturer's fairness concern degree is getting weaker. Otherwise, $\theta$ closer to 1 means the manufacturer's fairness concern degree is getting stronger.

Substituting $\pi_{m}$ and $\pi_{e}$ in $U_{m}$, we express the manufacturer's utility function as

$$
U_{m}=(1+\theta)\left(\frac{p q+T h-\rho q-c q-t h^{2}}{2}\right)+\theta \delta\left(\frac{k s^{2}}{2}-\rho q\right) .
$$

In this case, the manufacturer's decision is not based on profit, but utility. The manufacturer tries to maximize its utility. By backward induction, we obtain the optimal solution of this model as follows.

Theorem 3. In the decentralized decision model with government carbon subsidies and manufacturer's fairness concerns, the optimal product sales price is

$$
\begin{aligned}
p^{s f *}= & (c+\rho)+\left(d_{3}^{2}-t d_{1}\right) \cdot t \cdot \frac{\rho}{k} \cdot\left(\frac{d_{2}}{2 t d_{1}-d_{3}^{2}}\right)^{2} \\
& +\frac{t\left[D-d_{1}(c+\rho)\right]+d_{3} T}{2 t d_{1}-d_{3}^{2}}-\delta \rho \cdot \frac{\theta}{1+\theta} \cdot \frac{d_{3}^{2}-t d_{1}}{2 t d_{1}-d_{3}^{2}} .
\end{aligned}
$$

The optimal carbon emission reduction level is

$$
\begin{aligned}
h^{s f *}= & d_{3} \cdot \frac{\rho}{k} \cdot\left(d_{3}^{2}-t d_{1}\right) \cdot\left(\frac{d_{2}}{2 t d_{1}-d_{3}^{2}}\right)^{2} \\
& +\frac{d_{3}\left[D-d_{1}(c+\rho)\right]+2 T d_{1}}{2 t d_{1}-d_{3}^{2}}-\frac{d_{1} d_{3} \delta \rho}{2 t d_{1}-d_{3}^{2}} \cdot \frac{\theta}{1+\theta} .
\end{aligned}
$$

The optimal service level is

$$
s^{s f *}=d_{2} \cdot \frac{\rho}{k} \cdot \frac{d_{3}^{2}-t d_{1}}{2 t \beta-d_{3}^{2}} .
$$

The manufacturer's optimal utility is

$$
\begin{aligned}
U_{m}^{s f *}= & T \cdot \frac{d_{3}\left[(1+\theta)\left(D-c d_{1}-\rho d_{1}\right)-\theta d_{1} \rho \delta\right]+d_{1}(1+\theta) T}{2 t d_{1}-d_{3}^{2}}+\frac{t}{2(1+\theta)} \cdot \frac{\left[(1+\theta)\left(D-c d_{1}-\rho d_{1}\right)-\theta d_{1} \rho \delta\right]^{2}}{2 t d_{1}-d_{3}^{2}} \\
& +\left(\rho d_{2}\right)^{2} \cdot \frac{\delta \theta}{2 k} \cdot\left(\frac{d_{3}^{2}-t d_{1}}{2 t d_{1}-d_{3}^{2}}\right)^{2}-\frac{t \rho^{2} d_{2}^{4}}{2 t d_{1}-d_{3}^{2}} \cdot \frac{1+\theta}{2 k^{2}} \cdot\left(\frac{d_{3}^{2}-t d_{1}}{2 t d_{1}-d_{3}^{2}}\right)^{2} .
\end{aligned}
$$

The platform's optimal profit is

$$
\begin{aligned}
\pi_{e}^{s f *}= & \frac{\left(\rho d_{2}\right)^{2}}{2 k} \cdot\left(\frac{d_{3}^{2}-t d_{1}}{2 t d_{1}-d_{3}^{2}}\right)^{2} \\
& +\rho d_{1} \frac{t\left[D-d_{1}(c+\rho)\right]+T d_{3}}{2 t d_{1}-d_{3}^{2}} \\
& -\frac{\theta}{1+\theta} \cdot \frac{t(1+\delta)\left(\rho d_{1}\right)^{2}}{2 t d_{1}-d_{3}^{2}} .
\end{aligned}
$$

The manufacturer's optimal profit is

$$
\begin{aligned}
\pi_{m}^{s f *}= & \frac{\left(t\left[D-d_{1}(c+\rho)\right]^{2} / 2\right)+T d_{3}\left[D-d_{1}(c+\rho)\right]+T^{2} d_{1}}{2 t d_{1}-d_{3}^{2}} \\
& +\rho^{2} d_{2}^{2} \cdot \frac{\delta}{k} \cdot \frac{\theta}{1+\theta} \cdot\left(\frac{d_{3}^{2}-t d_{1}}{2 t d_{1}-d_{3}^{2}}\right)^{2}-\frac{t \rho^{2} d_{2}^{4}}{2 k^{2}\left(2 t d_{1}-d_{3}^{2}\right)} \\
& \cdot\left(\frac{d_{3}^{2}-t d_{1}}{2 t d_{1}-d_{3}^{2}}\right)^{2} \\
& -\left(\frac{\theta}{1+\theta}\right)^{2} \cdot \frac{t \delta^{2} \rho^{2} d_{1}^{2}}{2\left(2 t d_{1}-d_{3}^{2}\right)} .
\end{aligned}
$$

The supply chain's optimal profit is 


$$
\begin{aligned}
\pi^{s f *}= & \frac{t\left[D-d_{1}(c+\rho)\right]^{2}+\left(d_{3}+2 \rho d_{1} t\right)\left[D-d_{1}(c+\rho)\right]+d_{1} T\left(1+2 \rho d_{3}\right)}{2\left(2 t d_{1}-d_{3}^{2}\right)}+\frac{\left(\rho d_{2}\right)^{2}}{2 k} \cdot\left(1+2 \delta \cdot \frac{\theta}{1+\theta}\right) \cdot\left(\frac{d_{3}^{2}-t d_{1}}{2 t d_{1}-d_{3}^{2}}\right)^{2} \\
& -\frac{t d_{2}^{2}\left(\rho d_{2}\right)^{2}}{2 k^{2}\left(2 t d_{1}-d_{3}^{2}\right)} \cdot\left(\frac{d_{3}^{2}-t d_{1}}{2 t d_{1}-d_{3}^{2}}\right)^{2} \\
& -\frac{t}{2} \cdot \frac{\theta}{1+\theta} \cdot \frac{\left(d_{1} \rho\right)^{2}}{2 t d_{1}-d_{3}^{2}}\left[2(1+\delta)+\delta^{2} \frac{\theta}{1+\theta}\right]
\end{aligned}
$$

Proposition 2. $s^{s f *}$ is independent of $\theta$, while $p^{s f *}, h^{s f *}$, $\pi_{m}^{s f *}, \pi_{e}^{s f *}$, and $\pi^{s f *}$ all decrease as $\theta$ increases.

Proof. See Appendix C.

The manufacturer employs fairness concern behavior to ensure its utility not damaged, with such available means as the product price and the carbon emission reduction level. Dominant in their relationship, the platform is reluctant to adjust its service level to ease up the manufacturer's concerns and will pay the price of reduced profit for this. With fairness concerns increasing, the manufacturer may make decisions irrationally aiming to increase its profit. Therefore, the manufacturer intends to decrease its production cost, no longer exerting effort to improve the low-carbon level of the product. At the same time, the manufacturer reduces the product sales price expecting to increase the sales volume and tries to take the low quality-low price route. As a result, the effect is counterproductive, which eventually leads to the profit decline of the platform, the manufacturer, and the supply chain. Thus, Proposition 2 suggests that the manufacturer's fairness concerns go against the whole supply chain and its members.

In a supply chain system, the manufacturer who pays too much attention to the profit gap and its utility will get the opposite effect. Therefore, during the actual operation, as long as its profit can be increased, it is not necessary to pursue the absolute profit fairness among members. On the one hand, the low-carbon product manufacturer should actively work closely together with the platform, play its role, and keep improving the low-carbon level of products; the platform, on the other hand, should guarantee the service level and customer size and so is the manufacturer's profit.

4.4. Model IV: Centralized Decision Model with Government Carbon Subsidies. Now, we consider the case when the manufacturer and the platform can cooperate to maximize the supply chain's overall profit, which forms a centralized decision mode. Under this mode with government's carbon subsidies, the supply chain's profit is

$$
\pi(p, h, s)=(T h+p q)-\left(c q+\frac{t h^{2}}{2}+\frac{k s^{2}}{2}\right) .
$$

And, its optimal solution is given below.

Theorem 4. In the centralized decision model with government carbon subsidies, the optimal product retail price is

$$
p^{c *}=\frac{k t\left(D+c d_{1}\right)+k T d_{3}-c\left(t d_{2}^{2}+k d_{3}^{2}\right)}{2 k t d_{1}-\left(t d_{2}^{2}+k d_{3}^{2}\right)} .
$$

The optimal carbon emission reduction level is

$$
h^{c *}=\frac{k d_{3}\left(D-c d_{1}\right)+T\left(2 k d_{1}-d_{2}^{2}\right)}{2 k t d_{1}-\left(t d_{2}^{2}+k d_{3}^{2}\right)} .
$$

The optimal service level is

$$
s^{c *}=d_{2} \cdot \frac{t\left(D-c d_{1}\right)+T d_{3}}{2 k t d_{1}-\left(t d_{2}^{2}+k d_{3}^{2}\right)} .
$$

The supply chain's optimal profit is

$$
\pi^{c *}=\frac{k t\left(D-c d_{1}\right)^{2}+T^{2}\left(2 k d_{1}-d_{2}^{2}\right)+2 k T d_{3}\left(D-c d_{1}\right)}{4 k t d_{1}-2\left(t d_{2}^{2}+k d_{3}^{2}\right)} \text {. }
$$

\section{Managerial Analysis}

In this section, we show how government carbon subsidies and the manufacturer's fairness concerns would affect the supply chain decisions by comparison of models in Proposition 3 through Proposition 7.

Proposition 3. $s^{c *}>s^{s *}=s^{s f *}$. Both $s^{s *}$ and $s^{s f *}$ increase with $\rho . s^{c *}, s^{s *}$, and $s^{s *}$ increase with $d_{3}$.

Proof. See Appendix D.

Proposition 3 implies that since the service level is only depended on the platform, it stays the same no matter the low-carbon product manufacturer has fairness concerns or not. As the platform's profit increases, it has more available money to improve the service level. Correspondingly, consumers' preference for low-carbon products helps the rise in service level in all three cases. This inspires the manufacturer that they should try to promote low-carbon products and let consumers favor low-carbon products, which will also drive the platform to improve its service. In this way, the manufacturer, even a follower in the supply chain, still can have effect on the leader to some extent.

Similar to the proof of Proposition 3, we give Propositions 4-6 without extra proofs.

Proposition 4. $h^{c *}>h^{s *}>h^{s f *}$. Both $h^{s *}$ and $h^{s f *}$ decrease with the increase in $\rho$, while $h^{c *}, h^{s *}$, and $h^{s f *}$ increase with $d_{3}$. 
Proposition 4 shows that the e-commerce supply chain system has the highest carbon emission reduction level in the centralized decision model, and that when the manufacturer has fairness concerns, its excessive focus on profit allocation has affected the motivation and enthusiasm to reduce carbon emission. As the profit gained by the platform increases, the low-carbon product manufacturer will cut down its carbon emission reduction level due to the decrease in obtained profit. Thus, in order to raise the carbon emission reduction level, the platform should reduce the commission, which will help the sale of low-carbon product. However, as consumers' preference for low-carbon products increases, no matter under the decentralized decision models with or without the manufacturer's fairness concerns, or the centralized decision model, efforts will be made to improve carbon emission reduction levels.

Proposition 5. $p^{c *}>p^{s *}>p^{s f *}$. Both $p^{s *}$ and $p^{s f *}$ decrease with the increase in $\rho$ while $p^{c *}, p^{s *}$, and $p^{s f *}$ increase with $d_{3}$.

Proposition 5 expresses that the highest price can be set in the centralized decision model because this mode has both the highest carbon emission level and the highest service level, which can be accepted by consumers. This result reflects the approval by consumers for the cost of the supply chain system to provide high-quality products. Among the three decision models, the manufacturer is most sensitive to the profit when it has fairness concerns. When the manufacturer's profit is affected, it will prefer the low-end development way, not actively improving the carbon emission level, while the platform's service level will not get improved, either, so the manufacturer can only choose the low-price strategy. In the decentralized decision models, with the platform's profit increasing, the manufacturer expects to increase its profit by reducing prices. It will not actually but will reduce the manufacturer's profit. This also exposes the disadvantages of decentralized decision and further discloses the fact that the platform's attempt to obtain profit by collecting too much commission does harm to the supply chain. With the rise in consumers' preference for low-carbon products, it is a good situation for low-carbon sales, which can promote the rise in commodity prices under three decision modes.

Proposition 6. $\pi^{c *}>\pi^{s *}>\pi^{s f *}$. Both $\pi^{s *}$ and $\pi^{s f *}$ decrease with the increase in $\rho$, while $\pi^{c *}, \pi^{s *}$, and $\pi^{s f *}$ increase with $d_{3}$.

Proposition 6 tells us that the supply chain's profit is the largest in the centralized decision model, the smallest when the manufacturer has the fairness concerns, and in between when the manufacturer does not have any fairness concerns. This result demonstrates that the manufacturer is more sensitive to profit allocation when having fairness concerns, and its performance in the supply chain is affected. When the platform's profit rises, the supply chain's one will decline in the decentralized decision models (whether with the manufacturer's fairness concerns or not). This relation further reflects the manufacturer's desire to share the profit reasonably. Otherwise, it will adopt a more uncooperative way in the supply chain. As consumers prefer low-carbon products more, the production and sales of low-carbon products are more supported, and then, the supply chain's profit will increase in the end.

Hence, the manufacturer's irrational fairness concerns go against the operation and coordination of the supply chain system. In practice, manufacturers should be guided to give up this irrational behavior and closely cooperate with the operation of the system.

\section{Proposition 7. $U_{m}^{s f *}$ increases as $\theta$ increases.}

Proof. See Appendix E.

As stated in Proposition 7, the manufacturer's utility will increase with the fairness concern coefficient. Fairness concerns, in some sense, are thereby proven to have positive effect in the supply chain decision. When the low-carbon product manufacturer focuses on the fairness of profit allocation, the platform will take the manufacturer's needs into account in its decision process after obtaining this information. This guides one way for the weak enterprise in the supply chain how to struggle for its benefit with the strong one.

\section{Low-Carbon E-Commerce Supply Chain Coordination Based on Government Carbon Subsidies}

It can be seen from the comparison in previous section that the government carbon subsidy mechanism helps increase the supply chain's profit. When government subsidies are applied, the centralized decision is better than other decentralized ones, regardless of with or without the manufacturer's fairness concerns. The centralized decision mode achieves the optimal profit for the system, while decentralized decision modes result in loss of efficiency due to the double marginalization effect. Thus, a specific coordination mechanism is necessary to be applied in this system.

Since cost and benefit are two key factors connecting the manufacture and the platform, we adopt indicators about them as coordination means and design the joint allocation contract of cost and profit to coordinate the system. The idea of this contract is to coordinate the benefits of both sides in this way: the platform adjusts the commission by the manufacturer's sales price and production cost, while the manufacturer pays part of government subsidies to the platform; besides that, the manufacturer and the platform appropriately share the costs for each other.

Under the joint allocation contract of cost and profit, on the one hand, we assume that the platform adjusts the commission to $\bar{\rho}$, pays the proportion $y(0 \leq y \leq 1)$ of the service cost, and leaves the remaining $(1-y)$ to the manufacturer; on the other hand, we assume that the manufacturer keeps the proportion $z(0 \leq z \leq 1)$ of government subsidies, giving others to the platform, and pays the proportion $x(0 \leq x \leq 1)$ of the low-carbon cost, leaving the remaining $(1-x)$ to the platform. Then, the profit of the manufacturer is 


$$
\pi_{m}^{c}=(p-\bar{\rho}-c) q+z T h-x \frac{t h^{2}}{2}-(1-y) \frac{k s^{2}}{2} .
$$

The profit of the platform is

$$
\pi_{e}^{c}=\bar{\rho} q+(1-z) T h-(1-x) \frac{t h^{2}}{2}-\frac{y k s^{2}}{2} .
$$

Theorem 5. The joint allocation contract of cost and profit can coordinate the e-commerce supply chain if $(\bar{\rho}, x, y, z)$ satisfies

$$
\left\{\begin{array}{l}
\bar{\rho}=(1-\phi)(p-c), \\
x=\phi \\
y=1-\phi \\
z=\phi, \quad(0<\phi<1) .
\end{array}\right.
$$

Proof. See Appendix F.

When the supply chain achieves coordination, the ratio of the manufacturer's profit to the platform's one is $\phi /(1-\phi)$. With this, we call $\phi$ profit allocation coefficient. $\phi(0<\phi<1)$ reflects the manufacturer's ability to negotiate with the platform. The larger the $\phi$ is, the more profit the manufacturer could obtain, the less the platform is, and vice versa. So, $\phi$ cannot be too large or too small. To make the coordination mechanism effective, we analyze its feasible condition as follows:

(1) In model II, the condition for the platform and the manufacturer to agree on the joint allocation contract is that their profit after coordination should not be less than before, respectively. This condition can be formulated as

$$
\left\{\begin{array}{l}
\pi_{m}^{c} \geq \pi_{m}^{s *} \\
\pi_{e}^{c} \geq \pi_{e}^{s *}
\end{array}\right.
$$

which is equivalent to

$$
\left\{\begin{array}{l}
\pi_{m}^{c}=\phi \pi_{c}^{*} \geq \pi_{m}^{s *}, \\
\pi_{e}^{c}=(1-\phi) \pi_{c}^{*} \geq \pi_{e}^{s *} .
\end{array}\right.
$$

So, $\phi$ has to satisfy

$$
\frac{\pi_{m}^{s *}}{\pi_{c}^{*}} \leq \phi \leq 1-\frac{\pi_{e}^{s *}}{\pi_{c}^{*}}
$$

(2) In model III, two conditions are needed for the platform and the manufacturer to agree on the joint allocation contract. One is that their profit should not decrease after coordination. Another is the manufacturer's utility should not fall because of coordination. This condition can be formulated as

$$
\left\{\begin{array}{l}
\pi_{m}^{c} \geq \pi_{m}^{s *} \\
\pi_{e}^{c} \geq \pi_{e}^{s *} \\
U_{m}^{c} \geq U_{m}^{s f *}
\end{array}\right.
$$

which is equivalent to

$$
\left\{\begin{array}{l}
\pi_{m}^{c}=\phi \pi_{c}^{*} \geq \pi_{m}^{s f *}, \\
\pi_{e}^{c}=(1-\phi) \pi_{c}^{*} \geq \pi_{e}^{s f *}, \\
U_{m}^{c}=\pi_{m}^{c}-\theta\left(\delta \pi_{e}^{c}-\pi_{m}^{c}\right)=\phi \pi_{c}^{*}-\theta\left[\delta(1-\phi) \pi_{c}^{*}-\phi \pi_{c}^{*}\right] \geq \pi_{m}^{s f *}-\theta\left(\delta \pi_{e}^{s f *}-\pi_{m}^{s f *}\right) .
\end{array}\right.
$$

So, $\phi$ has to satisfy

$$
\frac{\pi_{m}^{s f *}}{\pi_{c}^{*}}+\frac{\theta \delta}{\theta(\delta+1)+1} \cdot \frac{\pi_{c}^{*}-\pi^{s f *}}{\pi_{c}{ }^{*}} \leq \phi \leq \frac{\pi_{c}{ }^{*}-\pi_{e}^{s f *}}{\pi_{c}{ }^{*}} .
$$

Since the difference of the lower bound and the upper one of $\phi$ is

$$
\begin{aligned}
& \frac{\pi_{c}^{*}-\pi_{e}^{s f *}}{\pi_{c}{ }^{*}}-\left[\frac{\pi_{m}^{s f *}}{\pi_{c}{ }^{*}}+\frac{\theta \delta}{\theta(\delta+1)+1} \cdot \frac{\pi_{c}{ }^{*}-\pi^{s f *}}{\pi_{c}{ }^{*}}\right] \\
& =\frac{\theta+1}{\theta(\delta+1)+1} \cdot \frac{\pi_{c}{ }^{*}-\pi^{s f *}}{\pi_{c}{ }^{*}},
\end{aligned}
$$

we have the following proposition.
Proposition 8. The value range of $\phi$ becomes larger as $\theta$ increases.

Proposition 8 shows that the manufacturer's fairness concerns are conducive to the coordination of the supply chain so that both the platform and the manufacturer can have much more choice during coordination.

\section{Numerical Examples}

In the following, we will put the coordination mechanism into practice by an example and analyze how this mechanism is influenced by other factors.

Suppose $c=200, T=1000, D=10000, d_{1}=20, d_{2}=2$, $d_{3}=10, k=5$, and $t=4$, which will be used in this section. 
7.1. Effectiveness Verification of the Coordination Mechanism. First, suppose $\rho=20, \theta=0.1$, and $\delta=100$. Refer Table 2 for the decision results before the coordination mechanism is applied.

In model II, the coordination mechanism $(\bar{\rho}, x, y, z)$ satisfies

$$
\left\{\begin{array}{l}
\bar{\rho}=560.356(1-\phi), \\
x=\phi \\
y=1-\phi \\
z=\phi
\end{array}\right.
$$

where $0.866 \leq \phi \leq 0.943$.

In model III, the coordination mechanism $(\bar{\rho}, x, y, z)$ satisfies

$$
\left\{\begin{array}{l}
\bar{\rho}=560.356(1-\phi), \\
x=\phi \\
y=1-\phi, \\
z=\phi,
\end{array}\right.
$$

where $0.913 \leq \phi \leq 0.956$.

Then, we use $\phi$ as the independent variable to compare the difference before and after coordination (see Figure 1).

As shown in Figure 1, in these two cases, the joint allocation contract of cost and profit has coordinated the supply chain system and achieved win-win cooperation.

The profit allocation coefficient, $\phi$, is the core parameter of the coordination mechanism $(\bar{\rho}, x, y, z)$. In the following three subsections, we will analyze how the coordination mechanism is influenced by other factors of the supply chain system and illustrate this influence through $\phi$.

7.2. Influence of $\rho$ on Coordination Mechanism. For the case without fairness concerns, we further suppose $\rho \in[1,20]$ and then obtain the relation between the bounds of $\phi$ and $\rho$ in this coordination mechanism, as demonstrated in Figure 2(a). Similarly, for the case with the manufacturer's fairness concerns, after supposing $\theta=0.1$ and $\delta=100$, we can also depict this relation, as demonstrated in Figure 2(b).

Figures 2(a) and 2(b) indicate that both the lower bound and the upper one of $\phi$ are negatively correlated to the commission, no matter whether the manufacturer has fairness concerns or not. As a result, the more commissions the platform collects, the less the manufacturer's profit share, and the more profit proportion the platform gets, which will be more and more beneficial to the platform. At the same time, it is known from Theorem 5 that the carbon emission reduction cost and platform service cost undertaken by the manufacturer will decrease, while the supply chain cost assumed by the platform will rise. This reflects the value of core enterprises of the supply chain. Besides that, as the commission increases, the span between the upper and lower bounds of $\phi$ becomes larger and larger, which facilitates coordination. This means that as the commission increases, the platform gets more profit, which gives the manufacturer more choices.

7.3. Influence of $\theta$ and $\rho$ on Coordination Mechanism. The feasible condition of our joint allocation contract is much more complicated when the manufacturer has fairness concerns because this mechanism will be influenced by $\theta$ and $\delta$, besides $\rho$. Suppose $\rho=10$ and $\delta=100$, then Figure 3(a) describes how the bounds of $\phi$ varies with $\theta \in[0.05,0.2]$. Moreover, suppose $\rho=10$ and $\theta=0.1$, then the relation between the bounds of $\phi$ and $\delta \in[100,200]$ is shown in Figure 3(b).

Figures 3(a) and 3(b) show that, in the case with fairness concerns, both the upper and lower bound of $\phi$ increase with $\theta$ or $\delta$, indicating that the manufacturer's fairness concerns play a role in the coordination. In contrast to this, the span between the upper and lower bound of $\phi$ is shrinking as $\theta$ or $\delta$ increases, which means fairness concerns of the manufacturer do not contribute to the design of the coordination contract so that the space for the platform and manufacturer to coordinate is getting smaller. The lower bound of $\phi$ increases rapidly with $\theta$ or $\delta$, so fairness concerns can significantly increase the manufacturer's minimum profit. Still, the platform, as the leader in the low-carbon e-commerce supply chain, will also protect its own profit margin. As far as $\theta$ and $\delta$ are concerned, the influence of former is more prominent; that is to say, the fairness concerns coefficient of the manufacturer has a bigger effect on the coordination mechanism.

7.4. Influence of $T$ on Coordination Mechanism. In this section, suppose $\rho=10, \theta=0.1$, and $\delta=100$.

The relation between $\phi$ and $T$ with or without fairness concerns is shown in Figures 4(a) and 4(b), respectively. Also, Figures 5(a) and 5(b) demonstrate how the span of $\phi$ between its upper and lower bound changes with $T$, respectively.

Figures 4(a) and 4(b) tell us that both the upper and lower bounds of $\phi$ increase with $T$, which is not related to fairness concerns of the manufacturer. This indicates that government carbon subsidies have a positive effect in the supply chain system, increasing the manufacturer's profit share. However, Figures 5(a) and 5(b) show that the span of $\phi$ between its upper and lower bound has a trend of rise-fall, which reflects that more government subsidies are not always the better. In the beginning, government subsidies are conducive to supply chain coordination, but when subsidies exceed a certain limit, it does not help coordinate the supply chain system any more. This is because with the continuous increase in $\phi$, the manufacturer occupies the more proportion of government subsidies, which leads to unfair allocation. Therefore, the platform will not cooperate as before. Furthermore, the comparison between Figures 5(a) and 5(b) also indicates clearly the manufacturer's fairness 
TABLe 2: Optimal decisions of different decision modes before coordination.

\begin{tabular}{|c|c|c|c|c|c|c|}
\hline & \multirow{2}{*}{ Price } & \multirow{2}{*}{ Carbon emission level } & \multirow{2}{*}{ Service level } & \multicolumn{3}{|c|}{ Profit } \\
\hline & & & & Manufacturer & Platform & Supply chain \\
\hline Model II & 760.36 & 1600.89 & 2.67 & $2.31 \times 10^{6}$ & $1.53 \times 10^{5}$ & $2.46 \times 10^{6}$ \\
\hline Model III & 699.75 & 994.83 & 2.67 & $1.40 \times 10^{6}$ & $1.18 \times 10^{5}$ & $1.52 \times 10^{6}$ \\
\hline Model IV & 798.60 & 1746.48 & 239.44 & - & - & $2.67 \times 10^{6}$ \\
\hline
\end{tabular}

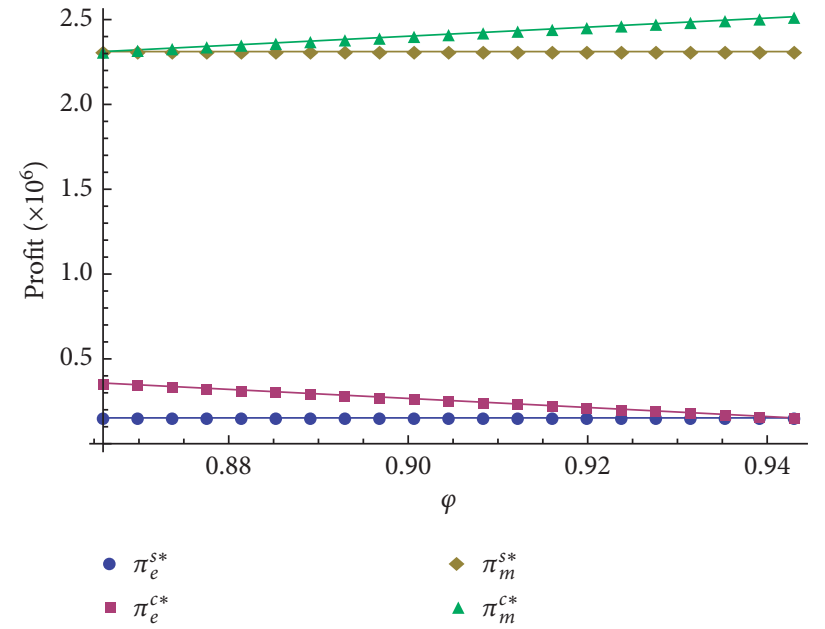

(a)

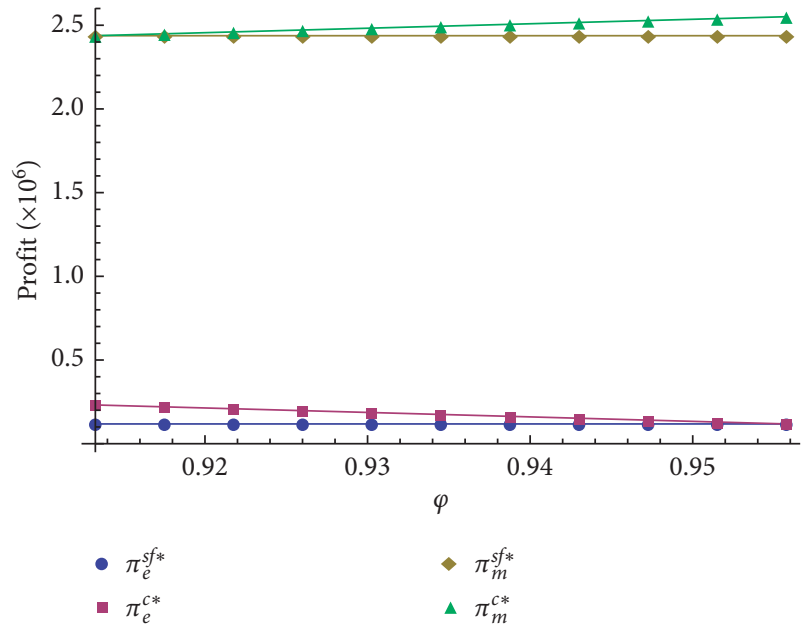

(b)

Figure 1: Comparison before and after coordination: (a) without fairness concerns; (b) with fairness concerns.

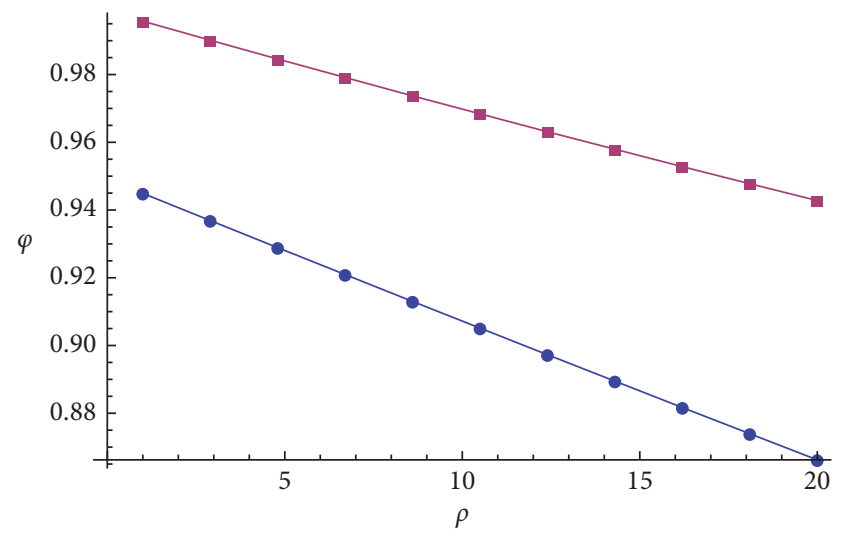

- Lower bound of $\varphi$

- Upper bound of $\varphi$

(a)

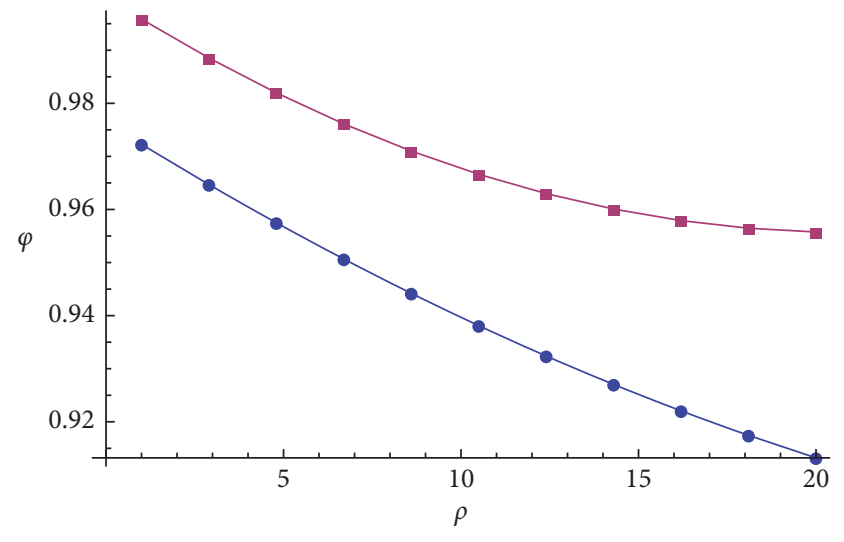

- Lower bound of $\varphi$

- Upper bound of $\varphi$

FIgURE 2: Change in bounds of $\phi$ with $\rho$ : (a) the case without fairness concerns; (b) the case with fairness concerns. 


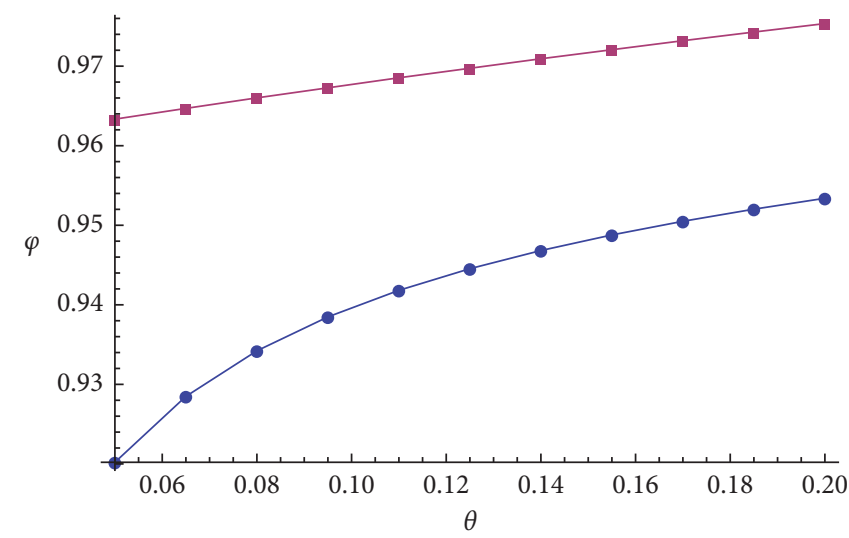

- Lower bound of $\varphi$

- Upper bound of $\varphi$

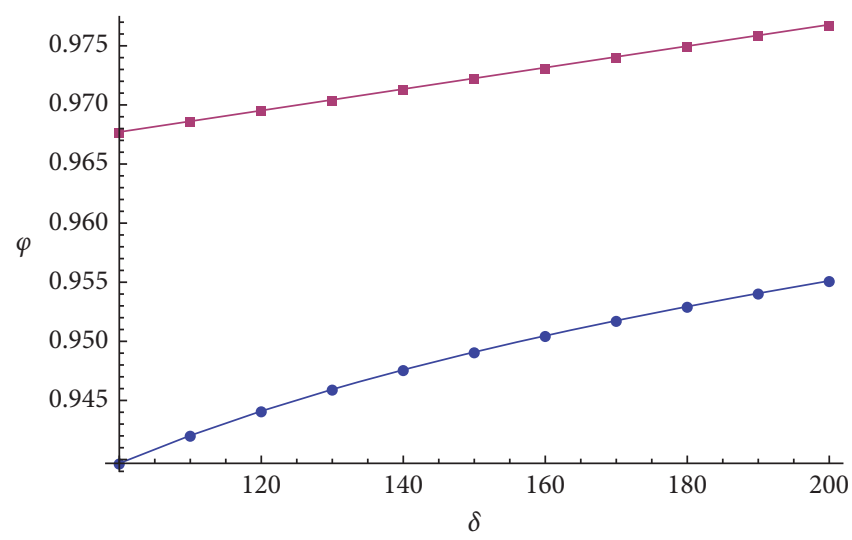

- Lower bound of $\varphi$

- Upper bound of $\varphi$

(a)

(b)

FIGURE 3: Change in bounds of $\phi$ in the mode with fairness concerns: (a) change in bounds of $\phi$ with $\theta$; (b) change in bounds of $\phi$ with $\delta$.

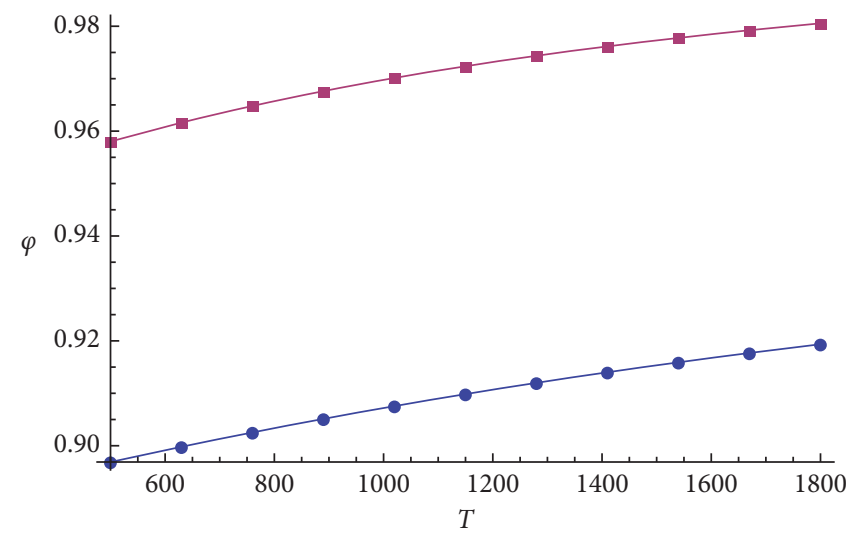

- Lower bound of $\varphi$

- Upper bound of $\varphi$

(a)

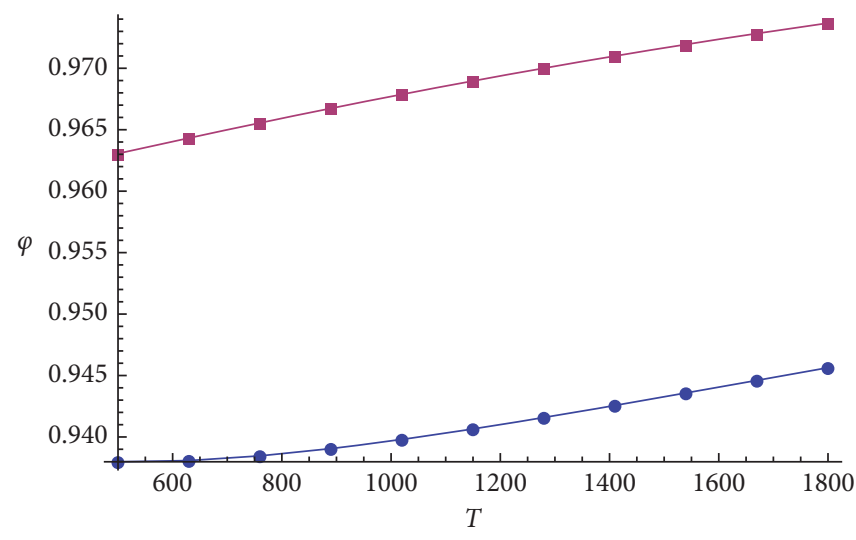

- Lower bound of $\varphi$

- Upper bound of $\varphi$

FIgURE 4: Change in bounds of $\phi$ with $T$ : (a) case without fairness concerns; (b) case with fairness concerns.

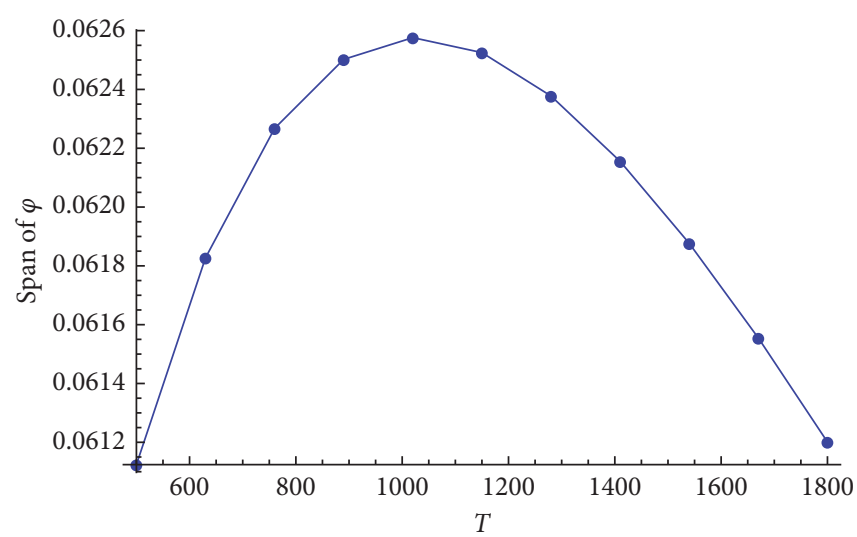

(a)

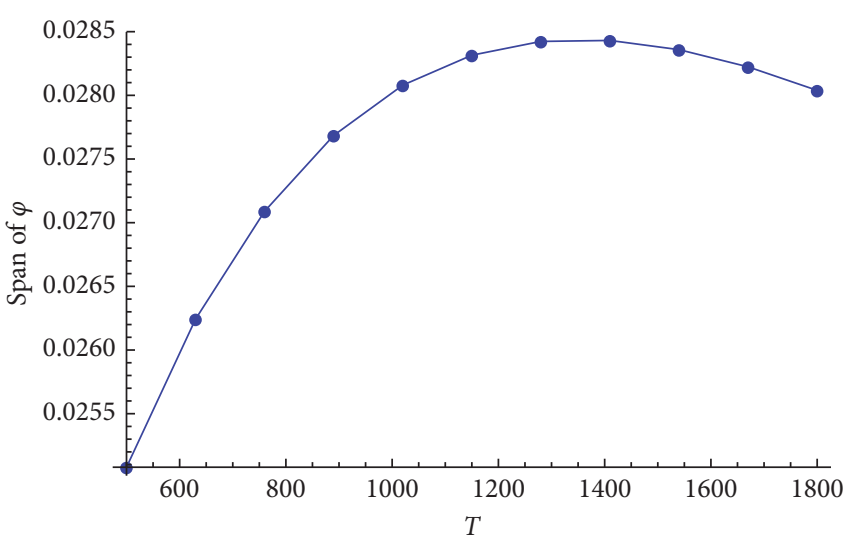

(b)

FIGURE 5: Change in span of $\phi$ with T: (a) case without fairness concerns; (b) case with fairness concerns. 
concerns can push the maximum span of $\phi$ rightward, which is a decision favorable to itself made by the manufacturer using fairness concerns.

\section{Concluding Comments}

In this paper, we address the decision and coordination of the e-commerce supply chain system composed of one small- and medium-sized low-carbon product manufacturer and one e-commerce platform. According to whether there are fairness concerns or government subsidies, different decision models are formulated. We reach the optimal decision for each model, design the contract to achieve the coordination of the supply chain system, and use numerical examples to analyze these decision models and the coordination strategy. We also reach the following constructive conclusions.

First, the promotion of low-carbon products will have win-win effects on the environment and economy. On the one hand, we have reached a consensus that carbon emission reduction helps protect the environment. One the other hand, consumers' preference for low-carbon products will be conducive to the operation of the low-carbon e-commerce supply chain. If consumers prefer low-carbon products, the service level, the carbon emission reduction level, the sales price, and the profit of the supply chain will all go up.

Second, government subsidies have positive effects when manufacturers do not have fairness concerns. The government gives some subsidies to low-carbon product manufacturers, which can get benefited obviously. Manufacturers may use the governmental support of carbon subsidies as an attractive feature to attract consumers. As a good result, the product price and carbon emission reduction level can be significantly improved, and this can also lead to the green consumption trend. However, because the platform does not obtain direct subsidies, its service level has not been improved. Yet, the profit improvement of manufacturers from government subsidies can be passed on to the platform.

Third, manufacturers' fairness concerns are an effective way for them to advocate interests. After manufacturers express their fairness concerns, their utility will get better with the increase in the fairness concerns. This means that the platform can receive the fairness concern information released by manufacturers and will consider manufacturers' requirements in the decision process.

Fourth, when manufacturers have fairness concerns, their negative effects will offset the positive effects of government subsidies. Fairness concerns make manufacturers pay too much attention to the profit difference between their own and the platform, which will make them reduce costs and choose to take the low quality-low price shortcut. But, the result of this choice is counterproductive. It significantly affects the benefits of the supply chain, leading to the failure of both manufacturers and the platform. So, as the leader in the supply chain, the platform should properly adjust the commission and share parts of the manufacturer's lowcarbon cost. In this way, the manufacturer's fairness concerns can be pacified.

Last, government subsidies are only conducive to supply chain coordination to a specific extent. During the process of coordination, manufacturers give some of the government subsidies to the platform for facilitating centralized decision. However, when government subsidies exceed a specific limit, manufacturers earn too much share. This will lead to the decline of the cooperation from the platform and bring some difficulties to the supply chain coordination.

At present, we only take manufacturers' fairness concerns into account, but in practice, the platform will also have fairness concerns to strive for reasonable profit. Moreover, from the last proposition, we can see that government subsidies are not enough to make the supply chain smoothly coordinated. Therefore, we can consider the full use of carbon tax and other means. Research related to these topics will be further addressed in future studies.

\section{Appendix}

\section{A. Proof of Theorem 1}

As has been assumed in the model background, in the Stackelberg game, the platform first determines its service level; then, based on the platform's decision, the manufacturer gives the low-carbon product sales price and carbon emission reduction level.

The Hessian matrix of the manufacturer's profit with respect to sales price and carbon emission reduction level is

$$
H_{m}=\left[\begin{array}{ll}
\frac{\partial^{2} \pi_{m}}{\partial p^{2}} & \frac{\partial^{2} \pi_{m}}{\partial p \partial h} \\
\frac{\partial^{2} \pi_{m}}{\partial h \partial p} & \frac{\partial^{2} \pi_{m}}{\partial h^{2}}
\end{array}\right]=\left[\begin{array}{cc}
-2 d_{1} & d_{3} \\
d_{3} & -t
\end{array}\right] .
$$

Since $d_{3}^{2}<2 t d_{1}, H_{m}$ is negatively definite.

So, the response function of $p$ and $h$ can be obtained:

$$
\begin{aligned}
p^{b *} & =\frac{\left(D+c d_{1}+s d_{2}+\rho d_{1}\right) t-(c+\rho) d_{3}^{2}}{2 t d_{1}-d_{3}^{2}}, \\
h^{b *} & =\frac{\lambda\left(D-c d_{1}+s d_{2}-d_{1} \rho\right)}{2 t d_{1}-d_{3}^{2}} .
\end{aligned}
$$

After updating equation (5) with these two expressions and solving $\mathrm{d} \pi_{e} / \mathrm{d} s=0$, the authors reach the platform's optimal service level:

$$
s^{b *}=d_{2} \cdot \frac{\rho}{k} \cdot \frac{d_{3}^{2}-t d_{1}}{2 t d_{1}-d_{3}^{2}}
$$

After substituting $s^{b *}$ in the expression of $p^{b *}$ and $h^{b *}$, the authors have the optimal product sales price: 


$$
\begin{aligned}
p^{b *}= & (c+\rho)+d_{1} \cdot \frac{\rho}{k} \cdot\left(\frac{t d_{2}}{2 t d_{1}-d_{3}^{2}}\right)^{2} \\
& +t \cdot \frac{k\left[D-d_{1}(c+\rho)\right]-d_{2}^{2} \rho}{k\left(2 t d_{1}-d_{3}^{2}\right)} .
\end{aligned}
$$

And the optimal carbon emission reduction level of the manufacturer

$$
\begin{aligned}
h^{b *}= & d_{1} \cdot \frac{\rho}{k} \cdot \frac{d_{3}}{t} \cdot\left(\frac{t d_{2}}{2 t d_{1}-d_{3}^{2}}\right)^{2} \\
& +\frac{d_{3}}{k} \cdot \frac{k\left[D-d_{1}(c+\rho)\right]-d_{2}^{2} \rho}{2 t d_{1}-d_{3}^{2}} .
\end{aligned}
$$

Substituting $p^{b *}, h^{b *}$, and $s^{b *}$ in equation (5), the authors find the manufacturer's optimal profit is

$$
\begin{aligned}
\pi_{m}^{b *}= & t \cdot \frac{\left[D-d_{1}(c+\rho)\right]^{2}}{2\left(2 t d_{1}-d_{3}^{2}\right)}-\frac{t d_{2}^{4}}{2} \cdot\left(\frac{\rho}{k}\right)^{2} \cdot \frac{1}{2 t d_{1}-d_{3}^{2}} \\
& \cdot\left(\frac{d_{3}^{2}-t d_{1}}{2 t d_{1}-d_{3}^{2}}\right)^{2}
\end{aligned}
$$

The platform's optimal profit is

$$
\pi_{e}^{b *}=t \rho d_{1} \cdot \frac{D-d_{1}(c+\rho)}{2 t d_{1}-d_{3}^{2}}+\frac{\left(\rho d_{2}\right)^{2}}{2 k} \cdot\left(\frac{d_{3}^{2}-t d_{1}}{2 t d_{1}-d_{3}^{2}}\right)^{2} .
$$

The supply chain's optimal profit is

$$
\begin{aligned}
\pi^{b *}= & t \cdot \frac{\left[D-d_{1}(c+\rho)\right]\left[D-d_{1}(c-\rho)\right]}{2\left(2 t d_{1}-d_{3}^{2}\right)}+\frac{d_{2}^{2} \rho}{2} \cdot \frac{\rho}{k} \\
& \cdot\left(\frac{d_{3}^{2}-t d_{1}}{2 t d_{1}-d_{3}^{2}}\right)^{2}-\frac{t d_{2}^{4}}{2} \cdot\left(\frac{\rho}{k}\right)^{2} \cdot \frac{1}{2 t d_{1}-d_{3}^{2}} \cdot\left(\frac{d_{3}^{2}-t d_{1}}{2 t d_{1}-d_{3}^{2}}\right)^{2}
\end{aligned}
$$

\section{B. Proof of Proposition 1}

It can be obtained from Theorems 1 and 2 that

$$
\begin{aligned}
p^{s *}-p^{b *} & =\frac{T d_{3}}{2 t d_{1}-d_{3}^{2}}, \\
h^{s *}-h^{b *} & =\frac{2 T d_{1}}{2 t d_{1}-d_{3}^{2}}, \\
s^{s *}-s^{b *} & =\frac{\rho d_{2}}{k} \cdot \frac{d_{3}^{2}-t d_{1}}{2 t d_{1}-d_{3}^{2}}-\frac{\rho d_{2}}{k} \cdot \frac{d_{3}^{2}-t d_{1}}{2 t d_{1}-d_{3}^{2}}=0,
\end{aligned}
$$

$$
\begin{aligned}
\pi_{m}^{s *}-\pi_{m}^{b *} & =\frac{T d_{3}\left[D-d_{1}(c+\rho)\right]+T^{2} d_{1}}{2 t d_{1}-d_{3}^{2}}, \\
\pi_{e}^{s *}-\pi_{e}^{b *} & =\frac{T d_{1} d_{3}}{2 t d_{1}-d_{3}^{2}}, \\
\pi^{s *}-\pi^{b *} & =\left(\pi_{m}^{s *}-\pi_{m}^{b *}\right)+\left(\pi_{e}^{s *}-\pi_{e}^{b *}\right) \\
& =\frac{T d_{3}\left[D+d_{1}-d_{1}(c+\rho)\right]+T^{2} d_{1}}{2 t d_{1}-d_{3}^{2}}
\end{aligned}
$$

Since $2 t d_{1}>d_{3}^{2}$ and $D$ is a large enough number, $p^{b *}<p^{s *}, h^{b *}<h^{s *}, s^{b *}=s^{s *}, \pi_{m}^{b *}<\pi_{m}^{s *}, \pi_{e}^{b *}<\pi_{e}^{s *}$, and $\pi^{b *}<\pi^{s *}$. Proposition 1 holds.

\section{Proof of Proposition 2}

(1) Because $s^{s f *}=d_{2} \cdot(\rho / k) \cdot\left(d_{3}^{2}-t d_{1} / 2 t d_{1}-d_{3}^{2}\right)$, there is no $\theta$ in the expression of $s^{s f *}$. So, $s^{s f *}$ is independent of $\theta$.

(2) Since $(d / d \theta)(\theta / 1+\theta)=\left(1 /(1+\theta)^{2}\right)>0, \quad(\theta / 1+\theta)$ increases with $\theta$.

Thus,

$$
\begin{aligned}
p^{s f *}= & (c+\rho)+\left(d_{3}^{2}-t d_{1}\right) \cdot \frac{\rho t}{k} \cdot\left(\frac{d_{2}}{2 t d_{1}-d_{3}^{2}}\right)^{2} \\
& +\frac{\left[D-d_{1}(c+\rho)\right] t+d_{3} T}{2 t d_{1}-d_{3}^{2}}-\frac{\theta}{1+\theta} \cdot \frac{d_{3}^{2}-t d_{1}}{2 t d_{1}-d_{3}^{2}} \cdot \delta \rho,
\end{aligned}
$$

decreases with $\theta$.

(3) As $(\theta / 1+\theta)$ increases with $\theta$,

$$
\begin{aligned}
h^{s f *}= & d_{3} \cdot \frac{\rho}{k} \cdot\left(d_{3}^{2}-t d_{1}\right) \cdot\left(\frac{d_{2}}{2 t d_{1}-d_{3}^{2}}\right)^{2} \\
& +\frac{d_{3}\left[D-d_{1}(c+\rho)\right]+2 T d_{1}}{2 t d_{1}-d_{3}^{2}}-\frac{d_{1} d_{3} \delta \rho}{2 t d_{1}-d_{3}^{2}} \cdot \frac{\theta}{1+\theta},
\end{aligned}
$$

decreases with $\theta$.

(4) Let $f(\theta)=(\theta / 1+\theta)$, then $\pi_{m}^{s f *}$ can be expressed as

$$
\pi_{m}^{s f *}=-\frac{t d_{1}^{2} \rho^{2} \delta^{2}}{2\left(2 t d_{1}-d_{3}^{2}\right)} f^{2}+\frac{\delta \rho^{2} d_{2}^{2}}{k} \cdot\left(\frac{d_{3}^{2}-t d_{1}}{2 t d_{1}-d_{3}^{2}}\right)^{2} f+A,
$$

where $A$ represents the items independent of $\theta$. So, $\pi_{m}^{s f *}$ is a downward parabola with $f$. If $\theta>0, f$ will be on the right of the symmetry axis of this parabola, 
which is the falling part. Therefore, $\pi_{m}^{s f *}$ decreases with $f$. Furthermore, $\pi_{m}^{s f *}$ decreases with $\theta$.

(5) As $(\theta / 1+\theta)$ increases with $\theta$,

$$
\begin{aligned}
\pi_{e}^{s f *}= & \frac{\rho^{2} d_{2}^{2}}{2 k} \cdot\left(\frac{d_{3}^{2}-t d_{1}}{2 t d_{1}-d_{3}^{22}}\right)^{2}+\rho d_{1} \frac{t\left[D-d_{1}(c+\rho)\right]+T d_{3}}{2 t d_{1}-d_{3}^{2}} \\
& -\frac{t(1+\delta)\left(d_{1} \rho\right)^{2}}{2 t d_{1}-d_{3}^{2}} \cdot \frac{\theta}{1+\theta},
\end{aligned}
$$

decreases with $\theta$.

(6) Since both $\pi_{m}^{s f *}$ and $\pi_{e}^{s f *}$ decrease with $\theta$, so does $\pi^{s f *}$

\section{Proof of Proposition 3}

(1) Since $s^{s *}=s^{s *}$ and $s^{c *}$ is the platform's optimal service level in the centralized decision model, $s^{c *}>s^{s *}=s^{s f *}:$ $s^{s *}=s^{s f *}=d_{2} \cdot \frac{\rho}{k} \cdot \frac{d_{3}^{2}-t d_{1}}{2 t d_{1}-d_{3}^{2}}=\frac{d_{2}}{k} \cdot \frac{d_{3}^{2}-t d_{1}}{2 t d_{1}-d_{3}^{2}} \cdot \rho$

(2) Thus, $s^{s *}$ and $s^{s f *}$ are direct proportional to $\rho$. That is to say, both $s^{s *}$ and $s^{s f *}$ increase with $\rho$.

(3) In the expression of $s^{c *}=d_{2} \cdot\left(t\left(D-c d_{1}\right)+\right.$ $\left.T d_{3}\right) /\left(2 k t d_{1}-\left(t d_{2}^{2}+k d_{3}^{2}\right)\right), \quad t d_{2}\left(D-c d_{1}\right)+T d_{2} d_{3}$ increases with $d_{3}$ while $2 k t d_{1}-\left(t d_{2}^{2}+k d_{3}^{2}\right)$ decreases with $d_{3}$. Thus, $s^{c *}$ increases with $d_{3}$.

Also, $\quad\left(\mathrm{d} s^{s *} / \mathrm{d} d_{3}\right)=\left(\mathrm{d} s^{s f *} / \mathrm{d} d_{3}\right)=d_{2} \cdot \rho k \cdot\left(\left(8 d_{1} d_{3}\right) /\right.$ $\left.\left(d_{3}^{2}-8 d_{1}\right)^{2}\right)>0$. Therefore, $s^{* *}$ and $s^{s f *}$ increase with $d_{3}$.

\section{E. Proof of Proposition 7}

Since

$$
\begin{aligned}
U_{m}^{s f *}= & \frac{(1+\theta) T d_{1}+\left[(1+\theta)\left(D-c d_{1}-\rho d_{1}\right)-\rho \delta \theta d_{1}\right] d_{3}}{2 t d_{1}-d_{3}^{2}} \cdot T+\frac{\left[(1+\theta)\left(D-c d_{1}-\rho d_{1}\right)-\rho \delta \theta d_{1}\right]^{2}}{2(1+\theta)\left(2 t d_{1}-d_{3}^{2}\right)} \cdot t+\frac{\delta \theta\left(\rho d_{2}\right)^{2}}{2 k} \\
& \cdot\left(\frac{d_{3}^{2}-t d_{1}}{2 t d_{1}-d_{3}^{2}}\right)^{2}-\frac{(1+\theta) t \rho^{2} d_{2}^{4}}{2 k^{2}\left(2 t d_{1}-d_{3}^{2}\right)} \cdot\left(\frac{d_{3}^{2}-t d_{1}}{2 t d_{1}-d_{3}^{2}}\right)^{2}, \\
\frac{d U_{m}^{s f *}}{d \theta}= & \frac{T d_{1}+d_{3}\left[\left(D-c d_{1}-\rho d_{1}\right)-d_{1} \rho \delta\right]}{2 t d_{1}-d_{3}^{2}} \cdot T \\
& +\frac{\left[D(1+\theta)-d_{1}(1+\theta)(\rho+c)-d_{1} \rho \delta \theta\right] \cdot\left[D(1+\theta)-d_{1}(1+\theta)(\rho+c)-d_{1}(\rho \delta \theta+2 \delta)\right]}{2(1+\theta)^{2}\left(2 t d_{1}-d_{3}^{2}\right)} \cdot t+\frac{\delta}{2 k} \cdot\left(\rho d_{2}\right)^{2} \\
& \cdot\left(\frac{d_{3}^{2}-t d_{1}}{2 t d_{1}-d_{3}^{2}}\right)^{2}-\frac{t \rho^{2} d_{2}^{4}}{2 k^{2}\left(2 t d_{1}-d_{3}^{2}\right)} \cdot\left(\frac{d_{3}^{2}-t d_{1}}{2 t d_{1}-d_{3}^{2}}\right)^{2} \\
= & T \cdot \frac{T d_{1}+d_{3}\left[\left(D-c d_{1}-\rho d_{1}\right)-d_{1} \rho \delta\right]}{2 t d_{1}-d_{3}^{2}} \\
& +t \cdot \frac{\left[D(1+\theta)-d_{1}(1+\theta)(\rho+c)-d_{1} \rho \delta \theta\right] \cdot\left[D(1+\theta)-d_{1}(1+\theta)(\rho+c)-d_{1}(\rho \delta \theta+2 \rho \delta)\right]}{2(1+\theta)^{2}\left(2 t d_{1}-d_{3}^{2}\right)} \\
& +\frac{\left(\rho d_{2}\right)^{2}}{2 k} \cdot \frac{k \delta\left(2 t d_{1}-d_{3}^{2}\right)-t d_{2}^{2}}{k\left(2 t d_{1}-d_{3}^{2}\right)} \cdot\left(\frac{d_{3}^{2}-t d_{1}}{2 t d_{1}-d_{3}^{2}}\right)^{2}>T \cdot \frac{T d_{1}+d_{3}\left[\left(D-c d_{1}-\rho d_{1}\right)-d_{1} \rho \delta\right]}{2 t d_{1}-d_{3}^{2}} \\
& +t \cdot \frac{\left(D(1+\theta)-d_{1}(1+\theta)(\rho+c)-d_{1} \rho \delta \theta\right] \cdot\left[D(1+\theta)-d_{1}(1+\theta)(\rho+c)-d_{1}(\rho \delta \theta+2 \rho \delta)\right]}{2(1+\theta)^{2}\left(2 t d_{1}-d_{3}^{2}\right)} \\
& +\frac{\left(\rho d_{2}\right)^{2}}{2 k} \cdot \frac{2 k t d_{1}-\left(k d_{3}^{2}-t d_{2}^{2}\right)}{k\left(2 t d_{1}-d_{3}^{2}\right)} \cdot\left(\frac{d_{3}^{2}-t d_{1}}{2 t d_{1}-d_{3}^{2}}\right)^{2}>0 . \\
& \\
& \\
& \\
&
\end{aligned}
$$


Thus, $U_{m}^{s f *}$ increases as $\theta$ increases.

\section{F. Proof of Theorem 5}

In the joint allocation contract of cost and profit, if $(\bar{\rho}, x, y, z)$ satisfies

$$
\left\{\begin{array}{l}
\bar{\rho}=(1-\phi)(p-c), \\
x=\phi \\
y=1-\phi \\
z=\phi, \quad(0<\phi<1),
\end{array}\right.
$$

the manufacturer's profit is expressed as

$$
\begin{aligned}
\pi_{m} & =\phi(p q-c q)-\phi \frac{t h^{2}}{2}-\phi \frac{k s^{2}}{2}+\phi T h \\
& =\phi\left[(p-c) q-\frac{t h^{2}}{2} t-\frac{k s^{2}}{2}+T h\right]=\phi \pi .
\end{aligned}
$$

And the platform's profit is

$$
\begin{aligned}
\pi_{e}= & (1-\phi)(p q-c q)-(1-\phi) \frac{t h^{2}}{2}-(1-\phi) \frac{k s^{2}}{2} \\
& +(1-\phi) T h=(1-\phi)\left[(p-c) q-\frac{t h^{2}}{2}-\frac{k s^{2}}{2}+T h\right]=(1-\phi) \pi
\end{aligned}
$$

Obviously, the profit of the manufacturer and platform is the affine function of that of the supply chain. Therefore, after this contract is applied, the supply chain system must be coordinated.

\section{Data Availability}

The data used to support the findings of this study are included within the article.

\section{Conflicts of Interest}

The authors declare that there are no conflicts of interest regarding the publication of this paper.

\section{Acknowledgments}

This paper was supported financially by the National Natural Science Foundation of China (71971129 and 71501111), Science and Technology Support Program for Youth Innovation of Colleges and Universities in Shandong Province (2019RWG017), and Philosophy and Social Science Project of Shandong Province (19BJCJ12).

\section{References}

[1] X. Zhu, M. Ren, W. Chu, and R. Chiong, "Remanufacturing subsidy or carbon regulation? An alternative toward sustainable production," Journal of Cleaner Production, vol. 239, p. 15, Article ID 117988, 2019.
[2] J. Li, W. Du, F. Yang, and G. Hua, "The carbon subsidy analysis in remanufacturing closed-Loop supply chain," Sustainability, vol. 6, no. 6, pp. 3861-3877, 2014.

[3] F. Qin, F. Mai, M. J. Fry, and A. S. Raturi, "Supply-chain performance anomalies: fairness concerns under private cost information," European Journal of Operational Research, vol. 252, no. 1, pp. 170-182, 2016.

[4] T. Li, J. Xie, X. Zhao, and J. Tang, "On supplier encroachment with retailer's fairness concerns," Computers \& Industrial Engineering, vol. 98, pp. 499-512, 2016.

[5] P. Jokela and A. Söderman, "Re-examining the link between fairness and commitment in buyer-supplier relationships," Journal of Purchasing and Supply Management, vol. 23, no. 4, pp. 268-279, 2017.

[6] J. Xie, L. Liang, L. Liu, and P. Ieromonachou, "Coordination contracts of dual-channel with cooperation advertising in closed-loop supply chains," International Journal of Production Economics, vol. 183, pp. 528-538, 2017.

[7] Q. Lu and N. Liu, "Pricing games of mixed conventional and e-commerce distribution channels," Computers \& Industrial Engineering, vol. 64, no. 1, pp. 122-132, 2013.

[8] Q. Lu and N. Liu, "Effects of e-commerce channel entry in a two-echelon supply chain: a comparative analysis of singleand dual-channel distribution systems," International Journal of Production Economics, vol. 165, pp. 100-111, 2015.

[9] Z. Liu, K. W. Li, B.-Y. Li, J. Huang, and J. Tang, "Impact of product-design strategies on the operations of a closed-loop supply chain," Transportation Research Part E: Logistics and Transportation Review, vol. 124, pp. 75-91, 2019.

[10] J. Tang, B. Y. Li, K. W. Li, Z. Liu, and J. Huang, "Pricing and warranty decisions in a two-period closed-loop supply chain," International Journal of Production Research, vol. 58, no. 6, pp. 1688-1704, 2020.

[11] Y. Su and W. Sun, "Analyzing a closed-loop supply chain considering environmental pollution using the NSGA-II," IEEE Transactions on Fuzzy Systems, vol. 27, no. 5, pp. 1066-1074, 2019.

[12] S.-M. Hosseini-Motlagh, S. Ebrahimi, and A. Jokar, "Sustainable supply chain coordination under competition and green effort scheme," Journal of the Operational Research Society, vol. 2019, p. 16, Article ID 1671152, 2019.

[13] J. Jian, Y. Guo, L. Jiang, Y. An, and J. Su, "A multi-objective optimization model for green supply chain considering environmental benefits," Sustainability, vol. 11, no. 21, p. 5911, 2019.

[14] S.-M. Hosseini-Motlagh, M. Johari, and R. Zirakpourdehkordi, "Grain production management to reduce global warming potential under financial constraints and time value of money using evolutionary game theory," International Journal of Production Research, vol. 2020, Article ID 1773562, 22 pages, 2020.

[15] S.-M. Hosseini-Motlagh, M. Nouri-Harzvili, T.-M. Choi, and S. Ebrahimi, "Reverse supply chain systems optimization with dual channel and demand disruptions: sustainability, CSR investment and pricing coordination," Information Sciences, vol. 503, pp. 606-634, 2019.

[16] K. Lamba, S. P. Singh, and N. Mishra, "Integrated decisions for supplier selection and lot-sizing considering different carbon emission regulations in big data environment," Computers \& Industrial Engineering, vol. 128, pp. 1052-1062, 2019.

[17] H. Peng and T. Pang, "Optimal strategies for a three-level contract-farming supply chain with subsidy," International Journal of Production Economics, vol. 216, pp. 274-286, 2019. 
[18] Z. Li, J. Zhang, Q. Meng, W. Zheng, and J. Du, "Influence of government subsidy on remanufacturing decision under different market models," Mathematical Problems in Engineering, vol. 2019, Article ID 9460315, 16 pages, 2019.

[19] J. Li, W. Du, F. Yang, and G. Hua, "The carbon subsidy analysis in remanufacturing closed-loop supply chain," Sustainability, vol. 6, no. 6, pp. 3861-3877, 2014.

[20] H. Liu, M. Lei, H. Deng, G. Keong Leong, and T. Huang, “A dual channel, quality-based price competition model for the WEEE recycling market with government subsidy," Omega, vol. 59, pp. 290-302, 2016.

[21] L. Deng, W. Li, and Z. Liu, "Different subsidies' impact on equilibrium decision-making of closed-loop supply chain," Journal of Industrial Engineering and Management, vol. 7, no. 5, pp. 1061-1075, 2014.

[22] D. Kahneman, J. L. Knetsch, and R. H. Thaler, "Fairness and the assumptions of economics," Journal of Business, vol. 59, no. 4, pp. 285-300, 1986.

[23] X. Qin, Q. Su, S. H. Huang, U. J. Wiersma, and M. Liu, "Service quality coordination contracts for online shopping service supply chain with competing service providers: integrating fairness and individual rationality," Operational Research, vol. 19, no. 1, pp. 269-296, 2019.

[24] L. Dai, X. Wang, X. Liu, and L. Wei, "Pricing strategies in dual-channel supply chain with a fair caring retailer," Complexity, vol. 2019, p. 23, Article ID 1484372, 2019.

[25] Z. Guan, T. Ye, and R. Yin, "Channel coordination under Nash bargaining fairness concerns in differential games of goodwill accumulation," European Journal of Operational Research, vol. 285, no. 3, pp. 916-930, 2020.

[26] X.-X. Zheng, Z. Liu, K. W. Li, J. Huang, and J. Chen, "Cooperative game approaches to coordinating a three-echelon closed-loop supply chain with fairness concerns," International Journal of Production Economics, vol. 212, pp. 92-110, 2019.

[27] Q. Li and B. Li, "Dual-channel supply chain equilibrium problems regarding retail services and fairness concerns," Applied Mathematical Modelling, vol. 40, no. 15-16, pp. 7349-7367, 2016.

[28] T. H. Cui, J. S. Raju, and Z. J. Zhang, "Fairness and channel coordination," Management Science, vol. 53, no. 8, pp. 1303-1314, 2007.

[29] D. Zhao, X. Zhang, T. Ren, and H. Fu, "Optimal pricing strategies in a product and service supply chain with extended warranty service competition considering retailer fairness concern," Mathematical Problems in Engineering, vol. 2019, p. 15, Article ID 8657463, 2019.

[30] Q. Li, X. Chen, and Y. Huang, "The stability and complexity analysis of a low-carbon supply chain considering fairness concern behavior and sales service," International Journal of Environmental Research and Public Health, vol. 16, no. 15, p. 2711, 2019.

[31] Q. Li, Y. Zhang, and Y. Huang, "The complexity analysis in dual-channel supply chain based on fairness concern and different business objectives," Complexity, vol. 2018, p. 13, Article ID 4752765, 2018.

[32] Q. Han and Y. Wang, “"Decision and coordination in a lowcarbon e-supply chain considering the manufacturer's carbon emission reduction behavior," Sustainability, vol. 10, no. 5, pp. 1-23, 2018.

[33] S.-M. Hosseini-Motlagh, M. Nouri-Harzvili, M. Johari, and B. R. Sarker, "Coordinating economic incentives, customer service and pricing decisions in a competitive closed-loop supply chain," Journal of Cleaner Production, vol. 255, p. 41, Article ID 120241, 2020.

[34] M. Johari and S.-M. Hosseini-Motlagh, "Coordination of social welfare, collecting, recycling and pricing decisions in a competitive sustainable closed-loop supply chain: a case for lead-acid battery," Annals of Operations Research, vol. 2019, Article ID 3292-1, 36 pages, 2019.

[35] M. Johari, S.-M. Hosseini-Motlagh, and M. Nematollahi, "Simultaneous coordination of review period and order-upto-level in a manufacturer-retailer chain," Journal of Industrial and Systems Engineering, vol. 10, pp. 1-17, 2017.

[36] S.-M. Hosseini-Motlagh, M. R. Nematollahi, M. Johari, and T.-M. Choi, "Reverse supply chain systems coordination across multiple links with duopolistic third party collectors," IEEE Transactions on Systems, Man, and Cybernetics: Systems, vol. 2019, p. 12, Article ID 2911644, 2019.

[37] S.-M. Hosseini-Motlagh, S. Ebrahimi, and R. Zirakpourdehkordi, "Coordination of dual-function acquisition price and corporate social responsibility in a sustainable closed-loop supply chain," Journal of Cleaner Production, vol. 251, p. 28, Article ID 119629, 2020.

[38] S.-M. Hosseini-Motlagh, M. Nematollahi, M. Johari, and B. R. Sarker, "A collaborative model for coordination of monopolistic manufacturer's promotional efforts and competing duopolistic retailers' trade credits," International Journal of Production Economics, vol. 204, pp. 108-122, 2018.

[39] M. Johari, S.-M. Hosseini-Motlagh, M. Nematollahi, M. Goh, and J. Ignatius, "Bi-level credit period coordination for periodic review inventory system with price-credit dependent demand under time value of money," Transportation Research Part E: Logistics and Transportation Review, vol. 114, pp. 270-291, 2018.

[40] J. Su, C. Li, Q. Zeng, J. Yang, and J. Zhang, "A green closedloop supply chain coordination mechanism based on thirdparty recycling," Sustainability, vol. 11, no. 19, p. 5335, 2019.

[41] J. Heydari, K. Govindan, and A. Jafari, "Reverse and closed loop supply chain coordination by considering government role," Transportation Research Part D: Transport and Environment, vol. 52, pp. 379-398, 2017.

[42] H. Peng, T. Pang, and J. Cong, "Coordination contracts for a supply chain with yield uncertainty and low-carbon preference," Journal of Cleaner Production, vol. 205, pp. 291-302, 2018.

[43] T. Nie and S. Du, "Dual-fairness supply chain with quantity discount contracts," European Journal of Operational Research, vol. 258, no. 2, pp. 491-500, 2017.

[44] X. Liu, X. Wang, L. Dai, and Y. Pan, "Research on supply chain performance based on retailers' fairness concerns: wholesale prices versus cost sharing of efforts," PLoS One, vol. 13, no. 10, Article ID e0204482, 2018.

[45] J. Jian, Y. Zhang, L. Jiang, and J. Su, "Coordination of supply chains with competing manufacturers considering fairness concerns," Complexity, vol. 2020, Article ID 4372603, 15 pages, 2020.

[46] O. Caliskan-Demirag, Y. Chen, and J. Li, "Channel coordination under fairness concerns and nonlinear demand," European Journal of Operational Research, vol. 207, no. 3, pp. 1321-1326, 2010.

[47] X.-X. Zheng, D.-F. Li, Z. Liu, F. Jia, and J.-B. Sheu, "Coordinating a closed-loop supply chain with fairness concerns through variable-weighted Shapley values," Transportation Research Part E: Logistics and Transportation Review, vol. 126, pp. 227-253, 2019. 
[48] Y. Wang, Z. Yu, and L. Shen, "Study on the decision-making and coordination of an e-commerce supply chain with manufacturer fairness concerns," International Journal of Production Research, vol. 57, no. 9, pp. 2788-2808, 2019.

[49] A. Nair and R. Narasimhan, "Dynamics of competing with quality- and advertising-based goodwill," European Journal of Operational Research, vol. 175, no. 1, pp. 462-474, 2006.

[50] D. Yao and J. Liu, "Competitive pricing of mixed retail and e-tail distribution channels," Omega, vol. 33, no. 3, pp. 235-247, 2005.

[51] B. Shen, R. Qian, and T.-M. Choi, "Selling luxury fashion online with social influences considerations: demand changes and supply chain coordination," International Journal of Production Economics, vol. 185, pp. 89-99, 2017.

[52] E. Fehr and K. M. Schmidt, "A theory of fairness, competition, and cooperation," The Quarterly Journal of Economics, vol. 114 , no. 3, pp. 817-868, 1999.

[53] E. Katok, T. Olsen, and V. Pavlov, "Wholesale pricing under mild and privately known concerns for fairness," Production and Operations Management, vol. 23, no. 2, pp. 285-302, 2014. 